\title{
Sub Tiberio quies? La situación política en Judea bajo los prefectos (6-41 e.c.), entre realidad e ideología
}

\author{
Fernando BERMEJo Rubio \\ UNED (Madrid) \\ fjlmbr@yahoo.es
}

Recibido: 30 de diciembre de 2014

Aceptado: 8 de abril de 2015

\section{RESUMEN}

Existen valoraciones llamativamente discrepantes sobre la situación política de Judea bajo la égida de los prefectos romanos (6-41 e.c.). Según una opinión, este habría sido un período de persistente agitación revolucionaria; según otra -más extendida-, habría sido tranquilo, de acuerdo a la aseveración de Tácito sub Tiberio quies. El presente artículo examina de nuevo críticamente las principales fuentes disponibles -en particular, la obra de Flavio Josefo, los evangelios canónicos y Tácito- con el objeto de ofrecer una reconstrucción histórica más fiable. El examen arroja resultados que ponen en cuestión nociones extendidas e insuficientemente matizadas acerca del período referido. A su vez, esto permite reflexionar sobre los factores extraepistémicos que pueden contribuir a explicar la génesis de tales nociones.

Palabras clave: Judea. Paz. Violencia. Roma. Prefectos. Prejuicios ideológicos.

\section{Sub Tiberio quies? Judaea's Political Situation under the Prefects (6-41 c.e.), between Reality and Ideology}

\begin{abstract}
Deeply conflicting views on the political situation of Judaea under the Roman prefects (6-41 c.e.) have been offered. According to some scholars, this was a period of persistent political unrest and agitation, whilst according to a widespread view it was a quiescent period of political calm (reflected in Tacitus' phrase sub Tiberio quies). The present article critically examines again the main available sources -particularly Josephus, the canonical Gospels and Tacitus-in order to offer a more reliable historical reconstruction. The conclusions drawn by this survey calls into question some widespread and insufficiently nuanced views on the period. This, in turn, allows a reflection on the non-epistemic factors which might contribute to explain the origin of such views.
\end{abstract}

Key words: Judaea. Peace. Violence. Rome. Prefects. Ideological prejudices.

Sumario: 1. Introducción. 2. La transformación de la imagen de Roma en Judea (ss. I a.e.c. - I e.c.). 3. El testimonio de Flavio Josefo (I): la Cuarta Filosofía. 4. El testimonio de Flavio Josefo (II): de Coponio a Marulo. 5. Evangelios canónicos (I): información circunstancial. 6. Evangelios canónicos (II): la historia central. 7. Releyendo a Tácito (Hist. V, 9, 2). 8. Conclusiones y reflexiones ulteriores. 
Para Diego Corral Varela, filólogo riguroso y escéptico

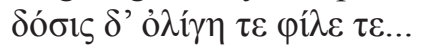

\section{Introducción}

Cuando se contempla el panorama historiográfico relativo al período que abarca los tres cuartos de siglo transcurridos desde la muerte de Herodes el Grande hasta la primera Guerra Judía, no podrá dejar de atraer la atención del observador atento un hecho llamativo. Por una parte, existe virtual unanimidad en postular el carácter turbulento del período que media entre la muerte de Herodes en 4 a.e.c. y la deposición y destierro de su hijo Arquelao en 6 e.c., así como el de las últimas décadas del gobierno de los procuradores de Judea, que tras la muerte de Agripa I (44 e.c.) provocaría un malestar creciente que desembocaría en la rebelión judía del 66. Por otra, sin embargo, existen visiones divergentes y aun contradictorias de la época en que Judea estuvo bajo la égida de los prefectos -la que corresponde a la etapa final del principado de Augusto, y a los gobiernos de Tiberio y Calígula-: ${ }^{1}$ mientras que algunos autores señalan el carácter incesantemente agitado del período, ${ }^{2}$ una conspicua mayoría insiste en su carácter tranquilo: aunque hubo conflictos, los judíos habrían recurrido sistemáticamente a las vías pacíficas. ${ }^{3}$ Una célebre expresión de Tácito, sub Tiberio quies, es a menudo aducida, explícita o implícitamente, como un argumento en respaldo de esta visión. ${ }^{4}$

Lo llamativo del caso no estriba solo en la aguda discrepancia interna del ámbito académico en relación al período, sino también en que la opinión mayoritaria postula un período de tranquilidad precisamente entre dos fases de extrema turbulencia. Es cierto que no parecen caber dudas del carácter tumultuoso del período siguiente a la muerte de Herodes ${ }^{5}$ ni del período de dominación romana directa bajo los procuradores, instaurado tras la muerte prematura del rey Agripa I. ${ }^{6} \mathrm{Y}$, por supuesto, es teóricamente posible que un oasis de tranquilidad se hubiera producido en Judea en el tiempo transcurrido entre dos tramos tan violentos, pero no resulta a priori el escenario más plausible, tanto más cuanto que la brutalidad de la represión de Varo, por mucho que haya sembrado el terror y servido de advertencia a los todavía deseosos de liberarse del yugo del Imperio, debe de haber dejado asimismo una profunda huella

1 Sobre la diferencia en el estatus de Judea en 6-41 e.c., cuando estuvo bajo dominio romano directo, subordinada a la provincia de Siria, y su pleno estatuto provincial en 44 o más tarde, cf. CoTTON 1999.

2 Cf. v. gr. Hengel 1971, 38, que se refiere a una época "agudamente revolucionaria"; MACCOBY 1973, 125, 147; Horsley 2003, 13, 35, 53-54; GRÜNEWALd 2004, 91.

3 Cf. v. gr. Giblet 1974; Barnett 1975; Jossa 1980; Guevara 1985, 259 (“época pacífica”); Cohen 2006 2, 158 ("For the next generation, Judea was quiet"); Brown 1994, I, 678; Sicre 2003, 51.

4 "Bajo Tiberio (hubo) tranquilidad" (Tac., Hist. V, 9, 2).

5 Cf. Jos., AJ XVII, 278-284; BJ II, 60-65. El legado de Siria Quintilio Varo intervino para reprimir las revueltas, haciendo crucificar a unos dos mil hombres ( $B J$ II, 75; $A J$ XVII, 295).

6 Ya bajo Tiberio Julio Alejandro los hijos de Judas el Galileo fueron crucificados ca. 46. Bajo Félix las crucifixiones son de nuevo moneda corriente, y se prolongan hasta el estallido de la guerra. 
de resentimiento en una parte no desdeñable de la población, y podría haber generado cierta oposición activa. ${ }^{7}$

La perplejidad es suscitada igualmente por el hecho de que, aunque hay que precaverse contra las generalizaciones apresuradas, son estas las que abundan en el caso que nos ocupa, y ello a pesar de que el período en cuestión abarque varias décadas. ${ }^{8}$ Ahora bien, si tales generalizaciones resultan ya sospechosas a priori, dada la complejidad del comportamiento de las colectividades humanas, son -como veremosdesmentidas por el análisis de las fuentes. De hecho, quienes postulan la existencia de "tranquilidad" en la época de los prefectos se ven compelidos a menudo a señalar excepciones, sin al parecer percatarse de que estas obligarían a matizar considerablemente $-y$, en el límite, a negar- la supuesta tranquilidad. ${ }^{9}$

Estas observaciones muestran la conveniencia de una relectura de las fuentes, con el objeto de aquilatar su significado y poder efectuar de este modo una reconstrucción más plausible y precisa de la situación sociopolítica de Judea en el período considerado. Lo que justifica esta tarea no es en este caso el descubrimiento de nuevas fuentes, sino la posibilidad de releer algunas de las ya disponibles - en particular, la obra de Flavio Josefo, los evangelios canónicos y el célebre pasaje de Tácito- de un modo relativamente novedoso y con un escrutinio más minucioso, también a la luz de algunos trabajos recientes. Veremos que las fuentes disponibles, críticamente consideradas, arrojan un resultado convergente que permite poner en cuestión nociones extendidas y no suficientemente matizadas acerca del período referido. A su vez, esto permitirá efectuar una reflexión sobre las razones extraepistémicas que pueden haber condicionado la génesis de tales nociones.

\section{La transformación de la imagen de Roma en Judea (ss. I a.e.c. - I e.c.)}

Antes de proceder a analizar las fuentes del s. I e.c., conviene examinar la transformación que la percepción de la imagen de Roma había experimentado en Judea. ${ }^{10}$ Al igual que el resto de los pueblos del Mediterráneo, ya en el s. II a.e.c. los judíos habían tenido contacto con el protectorado que Roma comenzaba a extender por la ecúmene. Esto es testimoniado en los libros de los Macabeos, en los que, en el contexto del conflicto con los Seléucidas, se narra el establecimiento de una alianza ( $\sigma v \mu \mu \alpha \chi i ́ \alpha)$ de Judas Macabeo con los poderosos romanos. ${ }^{11}$ La colaboración explica que en esta época la imagen de Roma en medios judíos fuera grosso modo positiva: aunque los abusos eran conocidos, Roma era admirada como un poder hegemónico y

\footnotetext{
7 Cf. RAPPAPORT 1992.

8 Incluso aquellos autores que hablan de un período "relativamente" tranquilo (cf. v. gr. WEBB 2009, 700) suelen olvidarse a renglón seguido del significado comparativo del adverbio.

9 Así lo ha señalado correctamente SCHWARTz 2013, 136.

10 Cf. De Lange 1978; Stemberger 1983; Hadas-Lebel 1987; Ayaso 1990, 264-304.

11 Cf. 1 Mac 8, 1-22; Jos., AJ XII, 414. Según 1 Mac 12, 1-16; 14, $17-18$ el pacto habría sido confirmado luego por Jonatán y Simón. Algunos historiadores han negado, no obstante, la existencia de un pacto con Roma anterior al tiempo de Hircano; cf. SHERwin-White 1984, 70-79.
} 
considerada como una magnitud susceptible de convertirse en un aliado protector; la imagen idealizada de la fides romana se impone. ${ }^{12}$

La idealización del otro, sin embargo, se produce con más facilidad en la distancia. La llegada de las legiones romanas a Eretz Israel en 63 a.e.c. y algunas de las acciones de Pompeyo - toma de la capital con ejecuciones, venta de numerosos habitantes como esclavos, profanación del Templo...- ${ }^{13}$ generaron una sensible alteración de esa imagen. La situación se agravaría luego con las acciones de Aulo Gabinio, Craso y C. Casio Longino. ${ }^{14}$ En el espacio de unas pocas generaciones se asiste a un progresivo deterioro de las relaciones que produce una sensible modificación de la percepción. La literatura judía del s. I a.e.c. testimonia, como veremos en lo que sigue, esta evolución.

Algunos datos contenidos en los Salmos de Salomón - una colección de 18 salmos pseudoepigráficos conservados en griego y siríaco, probablemente provenientes de una Vorlage hebrea y redactados en Judea en el s. I a.e.c.- inducen a pensar que estas composiciones describen acontecimientos sucedidos tras el asedio de Jerusalén por Pompeyo en 63 a.e.c. ${ }^{15}$ Independientemente de lo que se piense sobre el trasfondo histórico del Salmo $17,{ }^{16}$ es obvia la hostilidad que manifiesta respecto a los paganos. De hecho, esta composición refleja el anhelo por la aparición de un rey de linaje davídico, ${ }^{17} \mathrm{y}$ en ella se pide a Dios que le conceda fuerza no solo para ajustar cuentas con los pecadores (judíos) y "quebrantar a los príncipes injustos", sino también

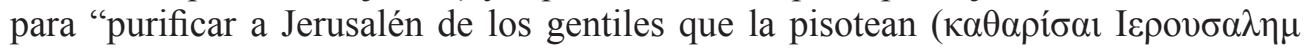

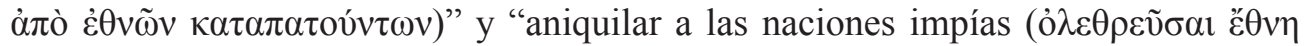
$\pi \alpha \rho \alpha ́ v o \mu \alpha) "{ }^{18}$

La hostilidad antirromana está testimoniada también en escritos hallados en Qumrán, en los cuales los "Kitti'im" (כתיים) son representados como el adversario principal de la comunidad. Aunque en algunas de estas obras los Kitti'im son identi-

121 Mac 8, 11: "Hacia sus amigos y los que se apoyaban en ellos han conservado su amistad ( $\mu \varepsilon \tau \grave{\alpha} \delta \delta \grave{\varepsilon} \tau \tilde{\omega} v$

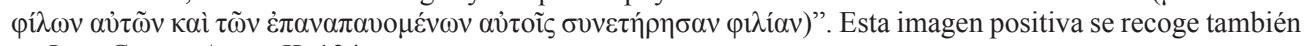
en Jos., Contra Apion. II, 134.

13 BJ I, 133-54; $A J$ XIV, 48-73.

14 Goodman 1987, 9-10.

15 En el salmo 2 hay una referencia clara a la muerte ignominiosa de Pompeyo (SalSl 2, 30-31), que coincide con lo narrado por Plutarco (Pomp. 77-80) y Dión Casio (Hist. 42, 5).

16 Algunos estudiosos han propuesto identificar al "malvado" y al "hombre extraño a nuestra raza

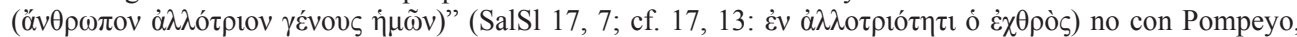
sino con Roma o con Herodes, en cuyo caso el texto correspondería a época herodiana. Cf. TRomp 1993; Puech 1992, 104, n. 21, y 129; AtKinson 1996; ID. 1998; ID. 1999; Nickelsburg 2005², 242-243. No obstante, AtKInSON (2004, 135-144) ha abogado por la identificación del "malvado" con Pompeyo.

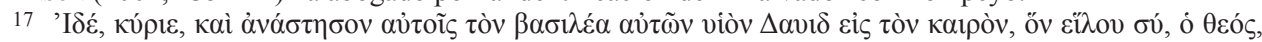

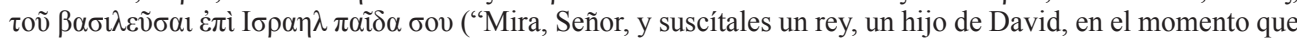
elijas, oh Dios, para que reine en Israel, tu siervo"): SalS1 17, 21.

18 SalS1 17, 22-25. Los Salmos de Salomón, y particularmente el 17, son dirigidos al mismo tiempo contra Roma y contra los oponentes judíos del autor (cf. PomYKala 1995, 163). El violento mesías de SalS1 17 halla un eco en el Targum a Gen 49,11-12: "Cuán hermoso es el Rey Mesías que ha de surgir de entre los de la casa de Judá. Ciñe los lomos y sale a la guerra contra los enemigos y mata a reyes con príncipes. Enrojece los montes con la sangre de sus muertos y blanquea los collados con la grasa de sus guerreros. Sus vestidos están envueltos en sangre: se parece al que pisa racimos" (Pérez Fernández 1981, 136). 
ficados como los reinos helenísticos -y en particular los Seléucidas-, varios pesharim provenientes del segundo tercio del s. I a.e.c. se refieren con ese término a los romanos -una identificación que halla ya un antecedente en Dan 11,30- ${ }^{19}$ Recientemente se ha propuesto una hipótesis sobre la composición del "Rollo de la Guerra" (1QM) según la cual una parte del texto (columnas 10-19, material litúrgico) fue añadido a mediados del s. I a.e.c. a un núcleo anterior, con el objeto de incluir una milagrosa intervención divina en la representación de la guerra definitiva contra los romanos. ${ }^{20}$

En el libro III de los Oráculos Sibilinos, Roma es dibujada como un poder opre-

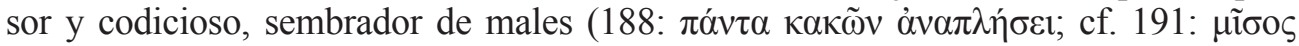
$\delta ’ \hat{\varepsilon} \xi \varepsilon \gamma \varepsilon \rho \varepsilon \bar{\imath}$, "suscitará el odio") y destinado a encontrar su fin: "Entonces el pueblo del gran Dios de nuevo será fuerte, y serán los que guíen en la vida a todos los mortales". ${ }^{21}$ Aunque se ha considerado tradicionalmente este libro como el estadio final de un proceso redaccional que habría comenzado en el s. II a.e.c., un estudio reciente postula que fue escrito por un judío en el s. I a.e.c., probablemente entre 80 y 40 a.e.c. ${ }^{22}$

Si bien a la muerte de Herodes la Roma de Augusto pudo aparecer como una instancia de apelación ante la arbitrariedad real -así parecería indicarlo la existencia de una delegación de notables de Judea en Roma para pedir autonomía y la disolución de la monarquía- y por tanto suscitar la esperanza en un protectorado clemente, la sangrienta intervención del legado de Siria -la llamada "guerra de Varo"-, que tiene lugar precisamente en la época de esta embajada, pone fin a tales expectativas. ${ }^{23}$ Esto parece testimoniado por la Asunción de Moisés, una obra escrita probablemente en Eretz Israel en el primer tercio del s. I e.c., en la que tras la mención de una cruel intervención romana ${ }^{24}$ se espera que comience el fin de los tiempos. ${ }^{25}$ Además, resulta llamativo que, incluso cuando uno se adentra en las fuentes del s. I escritas por judíos considerados filorromanos como Filón de Alejandría y Flavio Josefo, quepa detectar ciertas vetas críticas que dejan vislumbrar una percepción harto equívoca del Imperio. ${ }^{26}$

19 Los pesharim son textos interpretativos que actualizan el sentido de un pasaje bíblico. La identificación -operada ya en Dan 11, 30- se basa en alusiones que se hallan en el pesher de Habacuc. En 1QpHab 6, 1-4 se alude no solo a las tendencias imperialistas sino también a la veneración de estandartes, lo que parece una alusión a los signa; en 1QpHab 9, 4-7 hay una referencia a la conquista de Israel por Pompeyo. En el Pesher Nahum (4Q169 o 4QpNah) se halla un contraste entre los -anteriores- "reyes de Grecia" (מלכי יון) y "los gobernantes de los Kitti'im" (מושלי כתיים) en relación a la toma de Jerusalén. Cf. Collins 1995, 57-58; BrooKE 1991; Eshel 2001; ID. 2008, 163-179; HADAS-LeBel 1987, 747-755.

20 Cf. Schultz 2009. Aunque algunos autores consideran 1QM un texto solo litúrgico, otros han defendido que ese escrito y otros relacionados contemplan una batalla real; cf. Schultz 2012, 198, n. 5.

21 Cf. resp. OrSib 175-193; 194-195. "El pueblo del gran Dios" es una obvia referencia a los judíos.

22 Cf. BuitenWERF 2003, 126-130.

23 Cf. resp. $A J$ XVII, 300-314 y $A J$ XVII, 250-268, 286, 298.

24 La obra se conserva en latín, traducción de un original griego (tal vez versión, a su vez, de un original hebreo): In par [t] es eorum chortis venient et occidentes rex potens qui[a] expugnabit eos et duce[n]t captivos, et partem aedis ipsorum igni incendit, aliquos crucifigit circa coloniam eorum (Assumptio Mosis 6, 8-9). Suele pensarse que este pasaje se refiere a Varo (chortis como cohortes), aunque podría aludir a alguna otra intervención romana en el s. I e.c.; cf. TROMP 1993a, 204-205.

${ }_{25}$ Ex quo facto finientur tempora (Assumptio Mosis 6, 10).

26 Se ha señalado que, a pesar del supuesto filorromanismo de Filón (inferido de la descripción retórica del reinado de Augusto en la Legatio ad Caium), es necesario leer entre líneas -v. gr. Somn 2, 81-92; Plant 67-68- y percatarse de que la percepción que el filósofo tenía de Roma es menos positiva de lo que a menudo se ha supuesto. Además, aunque no hay mucho en su obra sobre soberanía política judía o mesianismo, sí hay 
Por supuesto, con obras como los Salmos de Salomón, los Oráculos Sibilinos o la Assumptio Mosis nos hallamos en un plano meramente literario, y no hay indicios de que sus autores o destinatarios se hicieran responsables de actividad antirromana; ${ }^{27}$ tanto menos, cuanto que la violencia imaginada en ellas quedaba reservada para el futuro, en un escenario con o sin figura mesiánica protagonista. Además, la concepción que se desprende de estos textos parece corresponder a grupos minoritarios, y no puede generalizarse sin incurrir en metonimias ilegítimas. ${ }^{28}$ El pragmatismo de las clases dirigentes -interesadas en preservar sus privilegios y por tanto en el mantenimiento de la paz- y también el del hombre común llevaron a muchos a contemporizar con el abrumador poder romano, ${ }^{29}$ y ello tanto más cuanto que, una vez que el recuerdo de Pompeyo y su profanación del Templo se fue disipando, habría sido fácil para los prorromanos basar su posición en el respeto romano por el culto judío. ${ }^{30}$ Hecho este caveat, no obstante, las fuentes mencionadas testimonian la existencia, en ciertos círculos de la Judea de finales de la República y comienzos del Alto Imperio, de una visión profundamente hostil hacia los dirigentes romanos y los gobernantes locales vasallos en Eretz Israel que no parece haber disminuido durante la última época herodiana, que es precisamente el período objeto de nuestro estudio. ${ }^{31}$

La existencia -y pervivencia- de estas actitudes antirromanas se hace más inteligible como expresión de un sentimiento nacionalista. En contra de una concepción extendida que ve en el nacionalismo un fenómeno moderno, en fuentes antiguas existen conceptos de identidad colectiva compatibles con una visión moderna del fenómeno. En el caso del judaísmo, la posesión de un texto -el Tanak o Biblia hebrea, que era también una historia nacional que se remontaba a los patriarcas y epónimos tribales-, la existencia de una lengua nacional -el hebreo-, un sistema jurídico e instituciones

alusiones a un futuro del pueblo judío en que este no permanecerá para siempre en un estatus subordinado (cf. v. gr. Quaest. Ex. 2, 76; De Praemiis et Poeniis 125-126, 163-171). Cf. Goodenough 1967, 5-7; Berthelot 2011. Incluso el prorromano Josefo -que en su momento juzgó la situación lo bastante intolerable como para tomar las armas contra Roma- no solo efectúa críticas (por ejemplo sobre la profanación del Templo: $B J$ I, 152; $A J$ XIV, 71-72), sino que postula de forma alusiva la caída del Imperio y un futuro renacimiento del judaísmo en una translatio imperii ( $A J$ IV, 127-128; X, 207); cf. SPILSBURY 2003. Sobre las sombras (pillajes y exacciones, provocación religiosa, represión sanguinaria, arbitrariedad...) en la imagen ideal de Roma en Josefo, cf. HaDAS-LeBel 1987, 801-814.

27 Téngase en cuenta que ya tras la ocupación romana en 63 a.e.c. hubo numerosas revueltas, dirigidas tanto contra los romanos como contra Hircano, algo comprensible también porque los dirigentes de muchas de ellas fueron hasmoneos. Herodes redujo la turbulencia a base de mano dura; cf. SHARON 2012.

28 No obstante, la esperanza en un rey davídico como el de SalSl parece haber estado muy extendida; cf. FREYNE 2009, 35.

29 Es sabido que esto ocurrió mayoritariamente en lugares como Séforis, Tiberíades y Escitópolis; cf. Jos., Vita 155-168, 381-384; AJ XVIII, 27; BJ II, 466-468.

30 Cf. Goodman 1987, 15. Sobre los judíos filorromanos, cf. Wilker 2007; ID. 2012. Muchos de los argumentos de los prorromanos se hallan en el discurso que Josefo atribuye a Agripa II en Jerusalén al inicio de la Guerra (BJ II, 345-401).

31 De hecho, en la Guerra Judía la comunidad de Qumrán acabaría destruida por los romanos, y hay indicios de oposición esenia a la dominación imperial (BJ II, 152-153; II, 567; III, 11); cf. De VAuX 1973, 24-41. "While the communities that composed Ps. Sol. 17, the Qumran texts, and Revelation are commonly regarded as pacifistic, their common image of a warrior messiah suggests that they looked forward with apparent eagerness to great bloodshed and annihilation of their enemies" (ATKINSON 1999, 460). Para una crítica de la noción del "pacifismo" esenio, cf. BATSCH 2004. 
compartidas proporcionaron el fundamento para construir creencias en una ascendencia y una cultura comunes, facilitando así la articulación ideológica de la resistencia al Imperio. ${ }^{32}$

\section{El testimonio de Flavio Josefo (I): la Cuarta Filosofía}

Además de a las tres orientaciones principales del judaísmo de su época-fariseos, saduceos y esenios-, en el libro XVIII de sus Antigüedades Judías Josefo se refirió a una "cuarta filosofía ( $\tau \varepsilon \tau \alpha \dot{\rho} \rho \tau \eta \eta$ mente en el momento en que Arquelao fue depuesto por Augusto, Coponio fue nombrado prefecto de Judea y Publio Sulpicio Quirino, el gobernador de Siria, procedió a elaborar un censo y el concomitante registro de la propiedad y tributación, es decir en el año 6 e.c. ${ }^{34}$ En este contexto, según informa Josefo, un galileo llamado Judas, basándose en la idea de que los judíos piadosos no deberían reconocer a otros señores junto a Dios, incitó a sus compatriotas a la rebelión, dando lugar a un movimiento novedoso.

Si bien la información proporcionada sobre la Cuarta Filosofía es relativamente breve y en diversos aspectos insatisfactoria -Josefo no trata, por ejemplo, del destino de Judas-, la terminología empleada deja claro que la oposición a Roma por la que se abogaba constituía una resistencia activa que no excluía la violencia. Tanto en Bellum como en Antiquitates Josefo utiliza el término ả ó$_{\sigma} \tau \alpha \sigma 1 \varsigma,{ }^{35}$ que ya desde Heródoto tiene en la lengua griega el significado de revuelta (violenta). En $A J$ XVIII, 4-5, las referencias a que Judas el Galileo y su colaborador Sadoc el fariseo hicieron un llamamien-

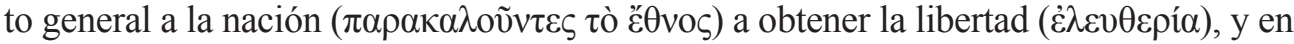

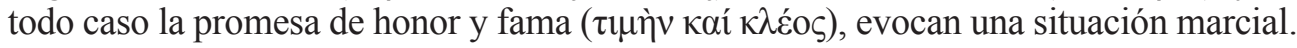
Además, según $B J$ II, 118 Judas reconvenía a sus conciudadanos no solo "por consentir pagar el tributo a los romanos" sino también "por tolerar señores mortales, teniendo

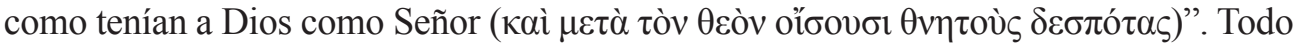
esto apunta a que, como se supone generalmente, la Cuarta Filosofía fue una ideología que no excluyó la violencia en la resistencia al Imperio. ${ }^{36}$

Por tanto, la opinión de los autores según los cuales la Cuarta Filosofía fue un fenómeno no violento que habría abogado únicamente por la resistencia pasiva no parece resultar plausible. ${ }^{37}$ Sin embargo, ello no implica que en el cuestionamiento de la opinión común no pueda haber una parte de verdad. No resulta justificado ni

32 Cf. Millar 1987, 147-148; Mendels 1992; Goodblatt 2006.

33 Cf. AJ XVIII, 9.23. Sobre este uso del término "filosofía", cf. Mason 1996, esp. 44-46.

34 Basándose en ciertas discrepancias entre Bellum y Antiquitates, se ha cuestionado la existencia misma de la Cuarta Filosofía; cf. McLAREN 2004. Por razones de espacio, no puedo abordar aquí de modo detallado las razones por las que esta propuesta no resulta convincente; cf. BERMEJO 2015a.

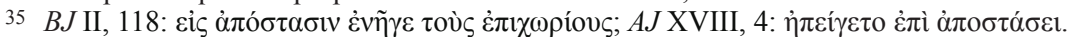

36 Cf. v. gr. Hengel 1976²; Nikiprowetzky 1989, 226; Marcus 1996, 12-16; Cohen 2006², 157-158.

37 Cf. Horsley $1993^{2}, 80$, que traduce $\alpha$ đó $\sigma \tau \alpha \sigma ı \varsigma$ no como "revuelta" sino como "resistencia"; en ello ha sido seguido por Crossan 1996, 116-117; HEARD - Evans 2000; y en apariencia también por FrEYNE 2009, 37 38. Para una crítica detallada de esta visión, remito a BERMEJo $2015 \mathrm{a}$. 
realista atenerse a una alternativa tajante -la Cuarta Filosofía abogó por la rebelión armada o renunció por principio al uso de armas-, y ello por varios motivos, entre los cuales cabe señalar la existencia de actitudes diversas respecto a los enemigos (paganos o internos) en la tradición judía, ${ }^{38}$ pero también el que la gravedad del llamamiento de Judas - que implicaba arriesgar la propia vida- debe de haber suscitado diversas opciones teóricas y prácticas entre aquellos a quienes resultó persuasiva, de acuerdo a sus diferentes sensibilidades: el ideal de aceptar la muerte antes que someterse pudo producir tanto combatientes por la resistencia como mártires. ${ }^{39}$ De hecho, en un contexto de resistencia a la dominación imperial, violencia y no violencia no suelen ser fenómenos mutuamente excluyentes. Esto es lo que puede inferirse de los testimonios disponibles para otros períodos de la historia judía. ${ }^{40}$ Así, por ejemplo, en la revuelta de los Macabeos contra Antíoco IV Epífanes se dieron la lucha armada y el martirio, y ambos fenómenos pueden ser considerados las dos caras de una ideología de resistencia: ${ }^{41}$ mientras el Primer Libro de los Macabeos se posiciona con firmeza a favor de la lucha armada, ${ }^{42}$ el Libro Segundo promueve más bien el martirio como el modo más justo de resistir al enemigo ${ }^{43}$ Resulta interesante percatarse de que todo indica que cada grupo vio al otro no como exclusivo, sino más bien como complementario, y que entre las varias opciones debe de haber prevalecido un sentimiento de profunda simpatía: en contraste con el enfoque colaboracionista, un denominador común de los modelos de resistencia fue que todos ellos estaban caracterizados por una voluntad común de oponerse al dominador pagano, y la disposición a ofrendar la propia vida por Dios y por la Torá.

La lección que cabe extraer de esta literatura es que la ideología de resistencia resulta ser compleja, fomentando tanto oposición activa como pasiva al dominio pagano. ${ }^{44} \mathrm{~A}$ esta luz, la idea de que la Cuarta Filosofía fue solo violenta -o no violentaparece el resultado de una simplificación excesiva, no respaldada ni por consideraciones elementales de orden sociológico y psicológico, ni por el examen filológico de las fuentes, ni por el conocimiento de otros episodios en la historia judía: los judíos piadosos de comienzos del s. I tenían a su disposición varios modelos de resistencia. Esto casa mejor con la opinión, defendida por algunos estudiosos, que ve en la "Cuarta Filosofía" más un movimiento inspirado por un ideal susceptible de materializarse de modos diversos, que como un grupo uniforme y estructurado con directrices claras.

38 Compárese el ejemplo de celo religioso violento de Pinjás -modelo en época seléucida para los Macabeos- con los desarrollos contenidos en Pseudo-Focílides 33-34 o en Filón, De vita Mosis I 314, textos en los que incluso la muerte legítima de enemigos es problematizada (VAN DEN Horst 1978, 136).

39 Obsérvese que un aspecto del llamamiento efectuado por Judas que puede haber provocado ulteriores discrepancias en el seno del movimiento es que el compromiso en la resistencia implicaba tomar posición no solo respecto a los romanos, sino también hacia correligionarios judíos.

40 Cf. Portier-Young 2011; Hezser 2013. Obsérvese asimismo que en la prefectura de Pilato hay testimoniados, junto a episodios violentos, otros de aparente resistencia pasiva.

41 Cf. FARMER 1956, 60-68.

42 Cf. esp. 1 Mac 2, 23-26.39-41.44-48; 3, 8; 9, 73; 14, 7.14.

43 Berthelot 2006, 110.

44 Berthelot 2006, 107. En 4 Macabeos, las categorías de la "guerra santa" se aplican a la estrategia del martirio; cf. 4 Mac 16, 16; 17, 11; BROWNLEE 1983, 287. 
Respecto a la repercusión de la Cuarta Filosofía, conviene observar que en ocasiones se ha sostenido que su eficacia estuvo restringida al momento de su eclosión, al suponerse que habría sido acallada de inmediato por el poder romano, de lo que se deduciría que una ideología y una praxis de resistencia no caracterizaron el período de administración de los prefectos. ${ }^{45}$ Aun admitiendo que una consideración fundada de esta cuestión solo puede ser emprendida una vez que los testimonios disponibles (tanto otro material pertinente contenido en Josefo como el resto de las fuentes) hayan sido analizados, es posible ya arrojar ciertas sospechas sobre la noción de la fugacidad del fenómeno. Ante todo, el hecho de que Josefo sitúe a la Cuarta Filosofía a la par con las otras corrientes del judaísmo -saduceos, fariseos y esenios- parece indicar ya que nos encontramos no ante un fenómeno meramente episódico sino ante una ideología consistente que no debe de haberse desvanecido durante décadas.

En segundo lugar, y en estrecha conexión con lo anterior, es necesario tener en

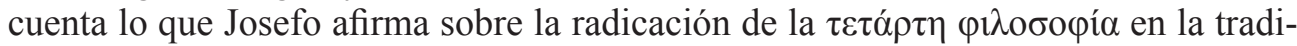
ción judía. Aunque en Bellum intenta presentar el movimiento como idiosincrásico, afirmando que no tenía "nada en común con los otros" ${ }^{46}$ en Antiquitates -una obra escrita cuando ya habían transcurrido un par de décadas tras la catástrofe militar y la necesidad de tomar precauciones había disminuido- afirma que esta corrien-

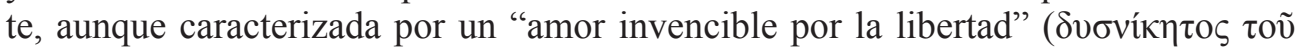
$\dot{\varepsilon} \lambda \varepsilon \varepsilon \theta \varepsilon \dot{\varepsilon} \rho 0 v$ É $\rho \omega \varsigma$ ), concordaba en todos los demás aspectos con las opiniones de los fariseos; de hecho, aquí un fariseo de nombre Sadoc es asociado a Judas como su principal colaborador. ${ }^{47} \mathrm{La}$ existencia de una amplia base común con otras corrientes del judaísmo contemporáneo casa perfectamente con el hecho de que, según cuenta Josefo, las nuevas ideas encontrasen considerable aceptación popular. ${ }^{48}$ Aun si presumiblemente fue reprimida, es difícil pensar que una ideología religiosamente inspirada y susceptible de ser caracterizada como un ala radical del fariseísmo haya sido simple y fácilmente eliminada. ${ }^{49}$

Además, Josefo atribuye al movimiento de Judas haber "sembrado las semillas" de las catástrofes venideras, y señala explícitamente la existencia de continuidad entre la Cuarta Filosofía y grupos de resistencia antirromanos posteriores..$^{50}$ Estos elementos de continuidad son, por un lado, genealógicos: Menajén, el líder de los zelotas, es presentado como "hijo" (viós) de Judas, y Eleazar ben Jaír, comandante en Masada,

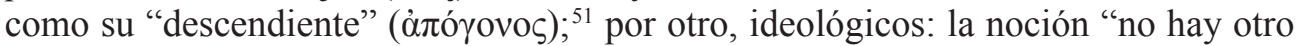
Señor que Dios", el anhelo por la libertad y la oposición al tributo reaparecen en la

45 Así Giblet 1974; Barnett 1975; Guevara 1985; entre muchos otros.

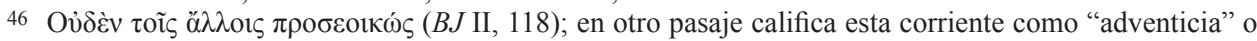

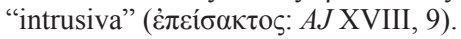

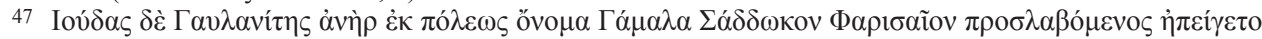

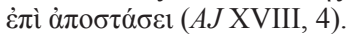

48 Cf. AJ XVIII, 6.

49 El origen fariseo de la Cuarta Filosofía es aceptado por numerosos estudiosos; cf. FreYNE 1998, 218; GabBa 2001, 133; Sмiтн 2001, 506-507. Obsérvese que, ya desde Julius Wellhausen, a menudo los Salmos de Salomón se han considerado también de origen fariseo; cf. ATKINSON 1999, 437, n. 4.

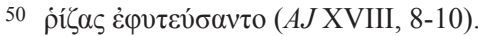

51 Cf. BJ II, 433; VII, 253. 
Guerra Judía. ${ }^{52}$ Obsérvese que la continuidad genealógica no se limita al período bélico: ${ }^{53}$ dos hermanos, Jacobo y Simón, crucificados en tiempos de Claudio bajo el procurador Tiberio Alejandro ca. 46-48, son denominados "hijos" ( $\pi \alpha \tilde{i} \delta \varepsilon \varsigma)$ de Judas. ${ }^{54}$ No podemos saber cuándo comenzaron estos su actividad, aunque dadas las noticias sobre otros casos, pudieron estar activos durante muchos años. ${ }^{55} \mathrm{Y}$ aunque la escueta información no nos permite determinar la causa de su castigo, dado el significado de la crucifixión en la Judea romana y la conexión con Judas, la razón previsible es algún tipo de actividad antirromana llevada a cabo con una ideología afín a la de la "Cuarta Filosofia". ${ }^{56}$

A la luz de lo anterior, y si bien la resistencia a Roma propugnada por Judas el Galileo no debe de haber sido ni mucho menos generalizada -pues la lucha contra la Cuarta Filosofía no conllevó una campaña militar que requiriese el envío de las legiones de Siria- y quizás no tan significativa como a veces se da a entender, ${ }^{57}$ todo apunta a cierta persistencia de la oposición a Roma, por soterrada e intermitente que haya sido. ${ }^{58}$ Por consiguiente, al menos la fase inicial del período considerado (6-41 e.c.) no parece haber sido en Judea precisamente tranquila.

\section{El testimonio de Flavio Josefo (II): de Coponio a Marulo}

Josefo no proporciona apenas información sobre el período de los prefectos previo a Poncio Pilato. El historiador dedica tan solo un breve párrafo a las actividades edilicias de los hijos de Herodes, los tetrarcas Filipo y Herodes Antipas. ${ }^{59}$ A continuación, presenta de modo sumario a las autoridades romanas de Judea: tras Coponio fue nombrado prefecto Marco Ambíbulo, y tras este Amnio Rufo, pero no se ofrecen detalles sobre su gobierno, o solo marginales. ${ }^{60}$ Otro caso llamativo es el de Valerio Grato, nombrado por el nuevo césar Tiberio sucesor de Amnio Rufo, y que es el predecesor directo de Pilato. Todo lo que se dice de Grato es que hizo varios cambios en el sumo sacerdocio en pocos años. ${ }^{61}$ Resulta llamativo que esta sea toda la información proporcionada sobre un prefecto que, según Josefo, retuvo su puesto durante once años.

52 Cf. BJVII, 323; 410-419. La oposición al pago del tributo está testimoniada por la acuñación de moneda propia durante los años de la revuelta. Cf. Mildenberg 1990; Rhoads 1976, 55; Hengel 1976², 120-123; McLaren 2003; Deines 2011, 433-34; Price 1992, 68s.

53 Pace Giblet 1974, 422: “il faut se représenter Judas le galiléen comme un théoricien qui a enseigné des doctrines politico-religieuses dont la véritable influence s'est fait sentir surtout à partir de Gessius Florus".

54 AJ XX, 102. Dada su procedencia judía, Tiberio Alejandro habría estado en una situación óptima para discernir la peligrosidad de determinados elementos.

55 El Eleazar al que Félix hizo prisionero había estado asolando el país durante veinte años (BJ II, 253).

56 Así v. gr. Hengel 1976², 353; Loftus 1977, 91.

57 Para algunos argumentos destinados a relativizar esa importancia, cf. RHOADs 1976, 51-52.

58 Obsérvese que Hch 5, 37, que suele ser citado como prueba de la desaparición del movimiento, habla de dispersión ( $\delta \varepsilon \sigma \kappa о \rho \pi i ́ \sigma \theta \eta \sigma \alpha v)$, no de aniquilamiento. La existencia de continuidad ha sido convincentemente argumentada por Hengel 1976²; cf. GabBa 2001², 133-134; Deines 2011.

59 BJ II, 168-169; AJ XVIII, 27-28.

60 De Rufo se dice solo que su administración estuvo marcada por la muerte de Augusto: AJ XVIII, 32.

61 AJ XVIII, 33-35. 
Aunque las razones de los cambios operados por Grato no son explicadas, ${ }^{62}$ se ha conjeturado que el hecho de que este depusiera a cuatro sumos sacerdotes en un período relativamente breve podría ser un indicio de ausencia de tranquilidad ya con anterioridad a la llegada de Pilato. ${ }^{63}$ Esta sospecha se incrementaría aún más si, a diferencia de lo que afirma el texto de Josefo -según el cual el prefecto retuvo el puesto durante once años-, ${ }^{64}$ Grato hubiera sido depuesto por Tiberio mucho antes y Pilato hubiera sido nombrado prefecto no el año 26 sino ca. 19 e.c. ${ }^{65}$

En todo caso, es menester precaverse ante una presentación demasiado negativa de los prefectos, en virtud del posible sesgo de Josefo. Esto puede resultar paradójico dada la conocida inclinación prorromana que este autor desarrolló, pero resulta fácil de entender. En efecto, en su intento por aparentar ser capaz de presentar la historia de la Guerra Judía sine ira et studio, ${ }^{66}$ Josefo necesitaba no solo canalizar la responsabilidad en el lado judío, sino también hasta cierto punto en el romano. Ahora bien, dada su dependencia de los Flavios - a quienes debía su supervivencia, la ciudadanía romana y la posibilidad misma de escribir-, Josefo estaba obligado a excluir a Vespasiano y a Tito de todo abierto reproche. Excluida la familia imperial, la crítica debió limitarse a los gobernantes romanos en Judea. Ahora bien, dado el alto rango (senatorial) de los gobernadores de Siria ${ }^{67}$ y el hecho de que sus influyentes familias seguían teniendo poder en Roma cuando Josefo escribía, a este le quedaba abierta la opción de atribuir la responsabilidad por parte romana a aquellas autoridades de rango inferior (ecuestre) cuyas familias no solían tener la influencia de la que gozaban los gobernadores. ${ }^{68}$ Esto explica que, cuando Josefo se ve compelido a cuestionar a las autoridades romanas, el blanco de sus críticas sea casi únicamente el ámbito de los prefectos de Judea. ${ }^{69}$

Josefo expone su relato de la prefectura de Pilato en una sucesión de episodios narrados en $A J$ XVIII, 55-89, que han sido examinados en numerosas ocasiones. ${ }^{70}$ No es mi intención exponerlos pormenorizadamente por enésima vez, sino solo llamar la atención sobre su carácter. En un trabajo clásico, Eduard Norden observó que

62 En cambio, cuando Quirino reemplaza a Joazar y nombra a Anán ben Sethi como sumo sacerdote, ello se explica como resultado de que Joazar había sido "dominado por una facción popular" (AJ XVIII, 26).

63 Smallwood 1981, 159-160: "the three brief tenures mirror some kind of popular unrest, in which the High Priests were involved in a way which made Gratus uncertain of their reliability from the Roman point of view"; cf. PRICE 1992, 6.

64 Cf. $A J$ XVIII, 35. En $A J$ XVIII, 89 se asevera que Pilato estuvo diez años en el cargo.

65 Cf. EISLER 1929-1930, I, 125-130; SCHWARTZ 1992, 182-217; LöNNQUIST 2000. Esta propuesta, empero, no es más que una hipótesis para la que no faltan objeciones; cf. Bond 1998, 1, n. 1.

66 Cf. BJ I, 1-9.

67 La importancia de los gobernadores era obvia, pues tenían confiada la defensa de la única gran provincia oriental del Imperio y el mantenimiento del limes con el objeto de impedir a los pueblos de Oriente el acceso al mare nostrum; sobre su condición de amici de los emperadores, cf. DĄBRowA 1998.

68 Cf. Mason 2005, esp. 78s.

69 Hay una excepción en el tono crítico del relato sobre el comportamiento de Vibio Marso con el rey Agripa I en $A J$ XIX, 326-363. Sin embargo, en este caso hay una explicación en el interés personal que tenía Josefo de halagar a Agripa II con un relato que honrase la memoria de su padre (EcK 2011, 51-53). También hay una excepción en el caso de Tiberio Alejandro, fácilmente comprensible dada su exitosa carrera política posterior y su apoyo a Vespasiano (EcK 2011, 53-54).

70 Cf. v. gr. MCLAREN 1991, 81-87. 
cada uno de los episodios que el historiador judío refiere sobre la época de Pilato es

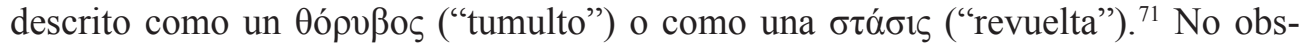
tante, a menudo se ha objetado a esto que el relato no prueba, en rigor, la existencia de resistencia armada, pues se limita a testimoniar por parte judía una resistencia no violenta ante acciones romanas percibidas como ultrajes. ${ }^{72}$ Ante la introducción en Jerusalén de estandartes con imágenes, la reacción judía consiste en una marcha pacífica a Cesarea, donde ante la amenaza de Pilato los judíos se muestran dispuestos a morir en defensa de la Ley. ${ }^{73}$ En la protesta por el uso de Pilato del tesoro del Templo para construir un acueducto en Jerusalén, es aquel quien reacciona causando una masacre. ${ }^{74}$

Esta presentación de los judíos como pacientes y no violentos ha servido a no pocos estudiosos modernos para ofrecer una imagen pacífica del período, pero resulta muy dudoso que sea legítimo utilizar tales noticias para extraer sin matizaciones inferencias genéricas sobre la situación sociopolítica. Ante todo, la presentación de una multitud perfectamente organizada que ante un ultraje a la Ley responde unánime durante días sin el menor asomo de violencia podría haber sido generada por el intento apologético de retratar a los judíos como fieles a la Ley y exquisitamente respetuosos con la autoridad imperial; cabe sospechar, pues, que las descripciones de Josefo constituyen una estilización de episodios en los que se dieron respuestas más complejas. De hecho, el incidente del acueducto es provocado por los excesos verbales de la multitud ${ }^{75}$ y es caracterizado como una $\sigma \tau \alpha \dot{\sigma} \sigma 1 \varsigma$, por lo que la presencia de alguna forma de violencia no puede excluirse. ${ }^{76}$ En segundo lugar, aunque Josefo presenta a los judíos protestando con ejemplar civismo contra el plan de Calígula de erigir una estatua suya en el templo de Jerusalén y declarando estar dispuestos a morir como mártires, ${ }^{77}$ al referirse al mismo episodio Tácito afirma que los judíos "recurrieron a las armas", y que solo la muerte de Calígula evitó que la cosa fuera a peor; así pues, quizás la reacción no fue tan pacífica como Josefo manifiesta. ${ }^{78}$ En tercer lugar, es improbable que una masacre tan brutal como la causada tras las protestas por el asunto del acueducto no generase un resentimiento susceptible de traducirse luego en algunos casos en recurso a la violencia. Además, el episodio final del ejercicio de Pilato consiste en un gravísimo incidente con los samaritanos, quienes, habiendo sido persuadidos por un visionario a acudir al monte Garizín, son atacados por el prefecto

71 NoRden 1913.

72 Cf. v. gr. Giblet 1974, 423; Guevara 1985, 87-96.

73 BJ II, 169-174; AJ XVIII, 55-59. "Aquí no hay el menor rastro de que algunos hubieran acudido a medios violentos. La demostración es completamente pacífica” (GuEvarA 1985, 91). Es probable que este incidente tuviera lugar el primer año de Pilato en su cargo; cf. McLaren 1991, 82-83.

74 BJ II, 175-177; $A J$ XVIII, 60-62. "Josefo afirma en ambos relatos que los muertos y heridos fueron judíos, lo que hace ver que ellos no usaron la violencia, sino que la padecieron” (Guevara 1985, 94).

75 Curiosamente, el propio Josefo señala en esta ocasión que en las multitudes suelen producirse abusos:

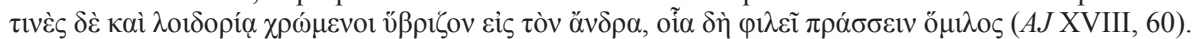

76 Como se ha señalado acertadamente, "his presentation of the violence as one-sided may reflect his desire to present the Jews as generally peaceable" (Marcus 2009, 1030).

77 Cf. BJ II, 196-197; AJ XVIII, 271; Phil., Legat. ad Caium 229-242.

78 Tac., Hist. V 9, 2. Schwartz 2013, 130-131. Sobre este aspecto, cf. infra, sección 7. 
con caballería e infantería fuertemente armada; ahora bien, Josefo afirma que los samaritanos se habían presentado armados. ${ }^{79}$

Por otra parte, conviene observar que los escasos incidentes sobre Judea mencionados por Josefo para la época de Pilato tienen lugar en un contexto jerosolimitano, donde las autoridades judías desempeñaron una función de control del descontento. Ahora bien, el historiador nada dice de otros posibles fenómenos, en particular los generados en contextos no urbanos ${ }^{80}$ Esta ausencia de información debería servir como una invitación a la cautela, tanto más cuanto que es en esos contextos no urbanos en los que la pervivencia de quienes decidieron resistir al poder de ocupación es más probable. ${ }^{81}$

A la luz de lo anterior, la pretensión de que del texto de Josefo es legítimo inferir sin más que la actitud del pueblo judío en la época de los prefectos fue exquisitamente pacífica supone pecar de simplismo. ${ }^{82}$ Dada la escasez de fuentes sobre el período, el uso de la obra del historiador judío es ineludible, pero ello no autoriza a emplearla sin los necesarios filtros críticos, tanto más cuanto que las necesidades apologéticas del autor filorromano son bien conocidas. En otras palabras, de la textualidad de Josefo no es legítimo a menudo proceder directamente a destilar historia.

Podría objetarse que Josefo pudo haber estado interesado en crear cierta impresión de turbulencia en tiempos de Pilato, sea para hacer más comprensible el giro consistente en el nombramiento por Roma de un rey judío, ${ }^{83}$ sea para hacer su historia más interesante, o por alguna otra razón. Esta objeción, no obstante, sería más persuasiva si careciéramos de información ulterior sobre el período, lo cual-como veremos-no es el caso.

\section{Evangelios canónicos (I): información circunstancial}

Los evangelios canónicos son obras escritas probablemente en la segunda mitad del s. I, cuyo carácter propagandístico y retórico -destinado a exaltar la figura de un predicador galileo- es obvio. La tendenciosidad de estos documentos y la gran cantidad de material legendario, hagiográfico y anacrónico que contienen han llevado a algunos estudiosos a negarles cualquier valor como fuentes. Sin embargo, todo apunta a que es posible extraer de los evangelios un núcleo histórico, y ello independientemente de si se acepta o no la interpretación que los considera una forma de Bíor helenís-

$79 \dot{\varepsilon} v$ ö $\pi \lambda$ orৎ ( $A J$ XVIII, 86-87). Resulta curioso que Guevara no mencione el dato relativo al armamento de los samaritanos. Cabe preguntarse, ciertamente, sobre el sentido de este dato, habida cuenta de que más tarde las protestas de las autoridades samaritanas ante el legado de Siria provocarán la llamada a capítulo del prefecto y su eventual destitución.

80 Como observó Hengel refiriéndose al dictum de Tácito: “Das taciteische 'sub Tiberio quies' wird den Kleinkrieg in der Wüste kaum miteinbezogen haben” (HeNGEL 1976², 344).

81 “Poder de ocupación" tiene aquí un sentido político, no militar. Las tropas auxiliares a cargo del prefecto estaban acantonadas en Cesarea Marítima, con solo un destacamento en Jerusalén.

82 En su Legatio ad Caium, que narra la embajada a Roma bajo Calígula, Filón evoca la época de Tiberio y pone en boca de los notables judíos esta advertencia a Pilato: "No provoques la revuelta, no provoques la

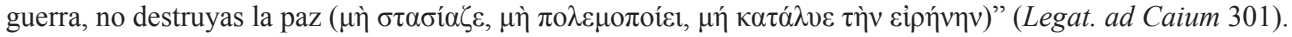

83 Nótese que Josefo comienza la historia de Agripa I poco después de la de Pilato. 
ticas. ${ }^{84}$ Esta posición no depende necesariamente de espurios intereses ideológicos -por ejemplo, del afán confesional por salvar la fiabilidad de los relatos fundacionales del cristianismo-, sino de consideraciones estrictamente metodológicas. ${ }^{85}$ Entre los criterios que cabe aplicar se hallan el de los patrones de recurrencia, el de plausibilidad histórica y el de dificultad. ${ }^{86}$

Los evangelios proporcionan algunas noticias referidas a acontecimientos en que tuvo lugar algún tipo de violencia por parte de la población judía o del prefecto romano -o de ambos-, pero que en la perspectiva de los autores no presentan una relación directa con la historia de Jesús. Son estas noticias, facilitadas al hilo de la narración principal, lo que designo como "información circunstancial". Esta información es especialmente relevante no solo por su naturaleza periférica -que no parece responder a intenciones o tendencias programáticas-, sino también porque el material diverge con respecto a un interés central de los autores de los evangelios, consistente en presentar a Jesús como un sujeto con un mensaje inocuo para el Imperio y desconectado de toda actividad sediciosa. A continuación mostraré que varias noticias de este tipo -todas ellas referidas a la prefectura de Poncio Pilato- ofrecen poderosos indicios de historicidad.

\subsection{Una masacre de galileos}

El primer pasaje a considerar es una breve información contenida en el Evangelio de Lucas (Lc 13, 1), que forma parte de su material especial (Sondergut), ${ }^{87}$ y que se refiere a una noticia que Jesús parece recibir en Galilea. El breve texto, en la voz del narrador, reza así: "Se presentaron en este mismo tiempo algunos que le informaron acerca de los galileos cuya sangre Pilato había mezclado con (la de) sus sacrificios

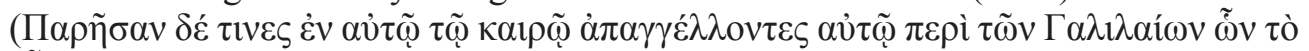

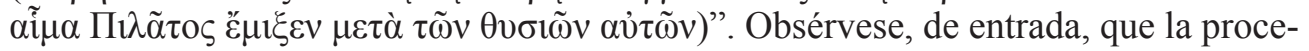
dencia galilea de Jesús le hace compatriota de las víctimas, lo cual podría explicar su interés por la noticia.

Dado que el texto parece referirse a los sacrificios rituales efectuados por los galileos, y a que estos solo podían ofrecerse en el Templo, los interlocutores de Jesús proceden presumiblemente de Jerusalén; ${ }^{88}$ en todo caso, transmiten un suceso violen-

\footnotetext{
84 BuRRIDGe 1992; FRICKENSCHMIDT 1997.

85 Para una respuesta sistemática a las objeciones contra la posibilidad de extraer material histórico de los evangelios, cf. THEISSEN - MERZ 1996, 96-120.

86 Sobre los patrones de recurrencia como indicios de historicidad, cf. Allison 2010, 10-30; Bermejo 2012. Sobre el criterio de plausibilidad contextual, cf. THEISSEN - WINTER 1997. El criterio de dificultad establece una presunción de historicidad cuando se detecta material que no solo no parece responder a intereses teológicos del autor, sino que los contradice de modo palmario; cf. BernheIm 1908, 509, 523.

87 En la hipótesis de las dos fuentes (aceptada mayoritariamente en la investigación, aunque existen hipótesis alternativas), el material especial es aquel que Lucas (y Mateo) no comparte con Marcos ni con Q (la fuente-Quelle- hipotética de la que provendría el material común a Lc y Mt no procedente de Mc).

88 Blinzler argumentó que, si el texto supone que las víctimas habían sido sacrificadas por los propios galileos, el episodio se referiría a la víspera de la fiesta de Pascua, la única ocasión en que los laicos podrían efectuar ellos mismos el sacrificio; BLINZLER 1957, 31; cf. SANDERS 1992, 135-138. Esto es tanto más plausible cuanto que el relato parece presuponer que Pilato se encontraba en Jerusalén, algo que solo tenía lugar en las
} 
to que es presentado como una novedad, y por tanto probablemente como muy reciente. En cuanto al contenido de la noticia, su sentido más plausible es que un grupo de galileos había sido masacrado por los hombres de Pilato, sea en el Templo, sea en una ocasión en que estos hombres se encontraban en Jerusalén, ${ }^{89}$ probablemente ca. 28-29. No es posible saber si el incidente implicó que los soldados entraran en el atrio del Templo, ${ }^{90} \mathrm{o}$ si la referencia sacrificial alude al estatuto de estos galileos como peregrinos y no implica necesariamente una violación del estatus sagrado del Templo de Jerusalén.

En la suposición de que Josefo no habría dejado de mencionar un incidente tan grave, se ha propuesto a menudo correlacionarlo con alguno de los episodios que el historiador narra sobre Pilato. Sin embargo, la fragilidad de estos intentos se muestra en que se ha querido relacionar el incidente prácticamente con todos esos episodios, lo cual resulta injustificado teniendo en cuenta las divergencias existentes entre los relatos. ${ }^{91}$

Una vez admitido lo infundado de toda equiparación con episodios ya conocidos, ${ }^{92}$ algunos autores han buscado explicar el silencio de Josefo mediante la negación de la historicidad de la noticia de Lucas. Sin embargo, esta conclusión carece de validez: no es legítimo suponer que la obra de Josefo sea un relato exhaustivo de lo sucedido en la época, pues de hecho presenta numerosas lagunas. ${ }^{93}$ La ausencia de este episodio puede explicarse de diversas maneras, sea porque las fuentes de Josefo no se lo transmitieron, sea porque él decidió omitirlo por alguna razón -por ejemplo, porque consideró que no añadía nada al carácter del gobernador romano, o porque no le pareció lo bastante relevante-.${ }^{94}$ Así pues, el silencio del historiador nada dice en contra de la autenticidad de la información de Lucas, que no solo está lejos de ser intrínsecamente improbable, sino que además parece corresponder perfectamente al Zeitgeist: la época de Pascua en Jerusalén era un tiempo especialmente propicio para generar arrebatos nacionalistas, dado que - como celebración y memorial de la liberación del pueblo de manos de un poder extranjero pagano- suscitaba comprensibles aspiraciones de liberación nacional. ${ }^{95}$

Esto hace probable que la noticia de Lucas refleje un episodio real en el que galileos religiosamente inspirados -quizás en la línea de la Cuarta Filosofía- causaron algún disturbio en Jerusalén y fueron reprimidos por las tropas de Pilato. A pesar de

fiestas, para poder intervenir en caso de eventual insurrección ( $B J$ II, 280s; $A J \mathrm{XX}, 107$ ); de lo contrario, el gobernador habitualmente residía en Cesarea ( $B J$ II, 171; $A J$ XVIII, 55-59).

89 Blinzler 1957, 30, n. 1. Sobre la presencia de galileos en Jerusalén, cf. Jos., BJ II, 2.5.30.

90 Esta posibilidad es aceptada por SMALLWOOD 1981, 163. La autora conjetura que este episodio puede referirse a la masacre ordenada por Pilato con ocasión de las protestas por el uso de dinero sagrado para la construcción del acueducto ( $B J$ II, 175-177; $A J$ XVIII, 60-62).

91 Blinzler 1957, 32-35; Bond 1998, 194-195.

92 Para críticas a otros intentos de identificación del episodio, cf. BlinZLer 1957, 35-42.

93 Cf. BLINZLeR 1957, 37.

94 Nótese que Josefo acostumbra a relatar masacres de cientos y aun miles de individuos.

95 De hecho, hubo varios tumultos en la ciudad precisamente en época de Pascua. Cf. v. gr. $A J$ XVII, 213s; $\mathrm{XX}, 105-112$. Josefo alude a la gran afluencia de peregrinos, lo que suponía la multiplicación de la población de Jerusalén, y por ende el aumento exponencial del riesgo de problemas de orden público. 
que la imagen de este que se deduce de Josefo y Filón es la de un gobernante duro, ${ }^{96}$ no es probable que el prefecto hubiera procedido a una matanza de galileos sin tener razones de peso para hacerlo: ${ }^{97}$ Pilato debía responder de sus actos en primer lugar ante el legado de Siria y en último término ante el emperador, ${ }^{98}$ y los comportamientos arbitrarios o claramente excesivos podían no solo ser políticamente contraproducentes sino también acarrear su llamada al orden y su destitución (como de hecho le ocurriría años más tarde, tras la represión de los samaritanos) ${ }^{99}$, o incluso servir de pretexto para alguna revuelta más considerable. Así pues, con toda probabilidad, los galileos mencionados en Lc 13, 1 deben de haber sido responsables de alguna acción insurgente, como ha sido reconocido por no pocos estudiosos. ${ }^{100}$

\subsection{Un motín en Jerusalén}

Un segundo pasaje significativo se conserva en los relatos de la pasión de Marcos y Lucas. Con ocasión de la presentación de la figura de Barrabás, se afirma que "se encontraba en prisión con los insurrectos, que en la insurrección habían perpetrado homicidio". ${ }^{101}$ El texto paralelo de Lucas $(\mathrm{Lc} 23,19)$ omite hablar de los insurrectos ( $\sigma \tau \alpha \sigma 1 \alpha \sigma \tau \alpha i)$, pero conserva el substantivo $\sigma \tau \alpha \dot{\sigma} \sigma{ }_{\zeta},{ }^{102}$ términos traducidos por Jerónimo como seditio y seditiosi.

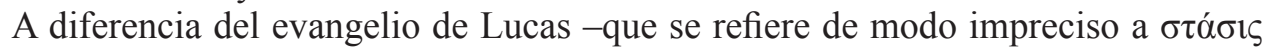
$\tau \iota \varsigma$ ("una insurrección")-, el de Marcos utiliza el artículo determinado tanto con "insurrección" como con "insurrectos". Esto podría significar que el acontecimiento y los personajes eran suficientemente conocidos. No obstante, es imposible determinar a qué incidente se refieren los evangelistas. Por ello se ha conjeturado, una vez más, que podría corresponder a alguno de los episodios que mencionan Josefo y Filón. ${ }^{103}$

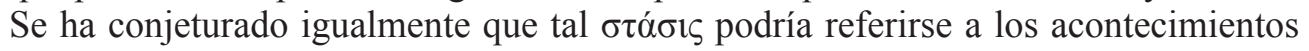

96 Cf. Phil., Legat. ad Caium 301s.

97 Como se desprende de la información proporcionada por Josefo en el episodio de los estandartes, Pilato sabía también ceder y no recurrir gratuitamente a la violencia.

98 Judea era parte de la provincia de Siria, y por tanto los prefectos estaban sometidos a la autoridad de los legados; cf. EcK 2007, 1-51.

99 Lo mismo le ocurrió al procurador Cumano. Cf. BJ II, 241-246; AJ XX, 125-136.

100 Blinzler 1957, 39; Lagrange 1941ㅎ․ 379; Cullmann 1961, 9; Bultmann 1970, 57; Vermes $2001,30$. BLINZLER 1957, 43-49 conjeturó que estos galileos podrían haber formado parte de los entusiastas que, según Jn 6, 15, quisieron proclamar rey a Jesús, y que en Jerusalén, a través de proclamas y/o acciones antirromanas, habrían provocado la reacción de Pilato.

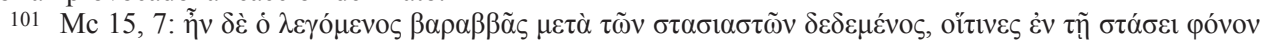
$\pi \varepsilon \pi \circ \imath \eta ́ \kappa \varepsilon \imath \sigma \alpha v$. Mientras que en el texto mayoritario no se dice que Barrabás mismo se hubiese hecho culpable de sedición y derramamiento de sangre, la variante de algunos manuscritos ( $\sigma v \sigma \tau \alpha \sigma 1 \alpha \sigma \tau \tilde{\omega} v)$ lo explicita. Obsérvese que $\sigma \tau \alpha \sigma \iota \alpha \tau \eta_{\zeta}$ es uno de los términos empleados por Josefo (v. gr. BJ VI, 157) para describir a los rebeldes antirromanos.

102 "Matt does not repeat Mark's reference to a riot, perhaps reflecting a post-Jewish-Revolt sensitivity that the memory of Jesus should not be associated even indirectly with political disturbance" (BROwN 1994, I, 797).

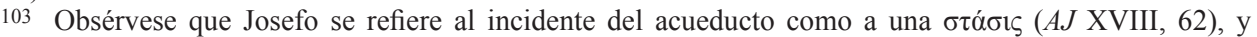
que cuando Filón narra la protesta de los judíos ante Pilato en el episodio de los escudos utiliza el verbo correspondiente ("No suscites la sedición"). 
ocurridos en los relatos de la entrada de Jesús en Jerusalén y en el del incidente del Templo. ${ }^{104}$

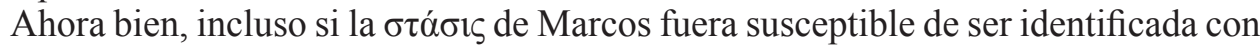
alguno de estos episodios, el aspecto llamativo es que -a diferencia de la narración que de ellos ofrece Josefo- tanto según Marcos como según Lucas en el episodio había tenido lugar al menos un acto violento con resultados fatales ( sea posible determinar la magnitud del derramamiento de sangre acaecido. Aunque la parquedad de la referencia no permite extraer conclusiones sobre el número de

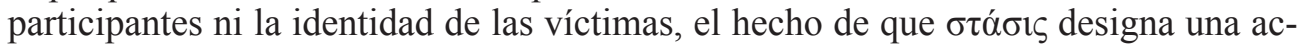
ción política permite efectuar la conjetura razonable de que la(s) víctima(s) fuera(n) o algún soldado al servicio de Roma, o algún judío considerado culpable de colaboracionismo.

\subsection{Una crucifixión colectiva}

Uno de los aspectos más obvios, pero paradójicamente menos tenidos en cuenta, de los relatos evangélicos de la pasión es el hecho de que todos ellos se refieren no a la ejecución de un solo hombre, sino a una crucifixión colectiva. Por supuesto, el interés de los autores de los textos $-\mathrm{y}$, curiosamente, también el de la mayor parte de autores modernos- está centrado en el sujeto que en el imaginario occidental se ha convertido en el Crucificado por antonomasia, pero precisamente por ello resulta tanto más significativo que se mencione a otros dos sujetos que padecen el mismo suplicio. ${ }^{105}$

Que este aspecto sea a menudo descuidado es llamativo, tanto más cuanto que la crucifixión, en la medida en que constituía una forma de ejecución ejemplarizante, destinada en Judea a insurgentes o sus cómplices y que buscaba infundir terror, solía ser aplicada del modo más natural a colectivos. ${ }^{106}$ La razón obvia es que se reservaba a humiliores, y preferentemente a delitos de maiestas imminuta, de acuerdo con la lex maiestatis desarrollada de varios modos en la transición de la República al Imperio. ${ }^{107}$ Con ocasión de actos de insurgencia -que son normalmente fenómenos colectivos-, Roma estaba comprensiblemente interesada en ejecutar no solo a los

104 Robert Eisler señaló que la aclamación recogida en Mc 11, 10 ("Bendito el reino que viene de nuestro padre David") para un autor que escribiese en Roma bajo Vespasiano o Tito no habría significado otra cosa que una proclamación sediciosa, y conjeturó que una versión anterior del evangelio, más tarde editada, podría haber utilizado explícitamente el término para describir los acontecimientos. Para ello, este autor compara Mc

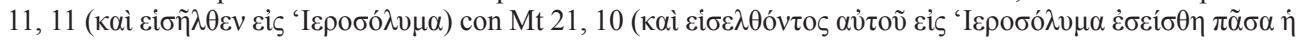

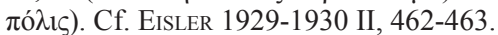

105 Cf. Mc 15, 27.32; Jn 19, 18. Solo ocasionalmente se ha planteado la posibilidad de que el número de crucificados fuera mayor que el que dan los evangelios, pero esta conjetura no es nada irrazonable. Cf. BAMMEL 1984, 443; LÉGASSE 1994, 144.

106 Cf. Jos., $B J$ II, 75; cf. $A J$ XVII, 295 (crucifixión de unos 2000 hombres por Varo); $A J$ XX, 102 (Tiberio Alejandro crucifica a los hijos de Judas el Galileo); $B J$ II, 241 (crucifixiones ordenadas por el gobernador de Siria Ummidio Cuadrato); $B J$ II, 253 (crucifixiones bajo el procurador Félix); $B J$ II, 306-308 (crucifixiones bajo Gesio Floro); y la mayor parte de los relatos de crucifixión correspondientes a la Guerra Judía (v. gr. $B J$ V, 449-451). Cf. Assumptio Mosis 6; Phil., in Flac. 72, 83-84.

107 Maiestas se refería a la dignidad del pueblo o el Estado, y por tanto a su soberanía. Con la llegada del principado, la maiestas pasó a ser entendida también como representada por el emperador, así como por otras figuras que detentaban el imperium, incluyendo a prefectos y procuradores que regían las provincias; cf. 
cabecillas, sino también a sus lugartenientes, ${ }^{108}$ así como -en ciertos casos- a sus cómplices y simpatizantes. ${ }^{109}$ Por otra parte, la crucifixión era un modo de ejecución efectuado con intenciones disuasorias, y el terror producido era tanto más efectivo no solo cuanto más cruel fuera, sino también cuanto más visible y ostentosa resultase. Como las otras testimoniadas en este período en Judea, la del Gólgota es una crucifixión colectiva.

Por supuesto, es menester plantearse de entrada si este dato resulta históricamente fiable, pues una elemental hermenéutica de la sospecha puede llevar a ponerlo en cuestión. Dado que la reflexión sobre las Escrituras y la necesidad de aplicarlas a la historia de Jesús al estilo de los pesharim llevó a la creación de cierto material contenido en los relatos de la pasión y la crucifixión, es legítimo preguntarse si la información relativa a los otros crucificados podría haber sido igualmente creada de un modo similar. ${ }^{110}$ Así, se ha sugerido que la traducción de la Septuaginta de un pasaje del

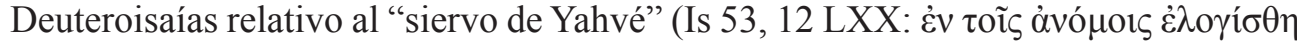
-"fue contado entre los sin ley") podría haber dado lugar a la elaboración marcana de la escena. Aunque esta propuesta no es irrazonable, se enfrenta a varias objeciones de peso. Ante todo, conviene no incurrir en Parallelenfreudigkeit: la noción de una persona rodeada de malhechores es general y vaga, y de hecho no hay semejanza verbal entre la traducción griega del pasaje de Isaías y la descripción que el evangelio de Marcos ofrece de los otros crucificados; ${ }^{111}$ una cosa es que los evangelistas hayan recordado o aludido a ese pasaje en sus escritos, y otra muy distinta que este haya generado tout court la noticia evangélica. En segundo lugar, la sugerencia de que la escena es el resultado de una creación libre no parece plausible, pues esto atentaría contra la tendencia de los evangelistas a aislar a Jesús como un personaje especial y único. ${ }^{112}$ Además, la invención de una escena en la que Jesús aparece acompañado por otros sujetos que sufren el mismo suplicio que él es improbable, pues ello habría podido generar gratuitamente dudas sobre la especial capacidad soteriológica de la crucifixión de Jesús - una idea en la que desde muy pronto hicieron hincapié los cristianos- ${ }^{113}$ Finalmente, y como ya se ha señalado, las crucifixiones suelen serlo de grupos, por lo que la descripción de una crucifixión colectiva resulta lo más natural.

Chilton 1955; Bauman 1967. Tácito (Ann. II, 50) asevera que bajo Tiberio la lex maiestatis se endureció, y en opinión de Suetonio (Tib. 58-59) Tiberio se excedió en su aplicación.

108 Así se afirma sobre Tacfarinas: non nisi duce interfecto requiem belli fore (Tac., Ann. IV, 25, 3).

109 Cf. Paulo, Sent. 5, 3, 4: Receptores adgressorum itemque latronum eadem poena adficiuntur qua ipsi latrones. Josefo se refiere a la elevada cifra no solo de sediciosos, sino también de quienes fueron declarados

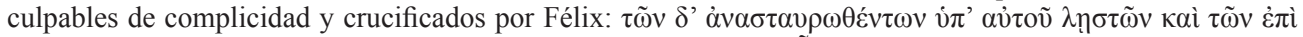

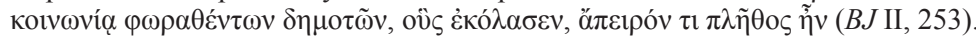

110 No hay razón alguna para dudar de la historicidad de la crucifixión de Jesús. No solo la descripción del procedimiento es internamente consistente (azotes previos, transporte del patibulum, uso de titulus) e históricamente plausible, sino que sería difícil explicar que los cristianos hubieran proclamado un mesías crucificado a menos que esto fuera un dato sólidamente asentado. Cf. WeBB 2009, 689-695.

111 Además, aunque Lucas es el único evangelio que cita Is 53, 12, uno de sus "malhechores" es dibujado con una luz favorable, y no como un ánomos (cf. Brown 1994 II, 970).

112 Cf. LÉGASSE 1994, 144.

113 En otras palabras, lo que podría ganarse mediante la creación del dato no parecería compensar en modo alguno las potenciales dificultades que crea. 
No parece haber razón convincente alguna, pues, para cuestionar la fiabilidad histórica de la noticia. ${ }^{14}$

La siguiente cuestión que debe ser determinada es la identidad de las víctimas. Si bien este aspecto apenas merece la atención de los autores -o los transmisores- de los relatos evangélicos, estos aportan una información que parece determinante. Marcos

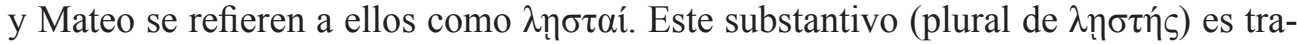
ducido generalmente por las Biblias al uso como "ladrones" o "bandidos" -como si el término se refiriese a criminales comunes-, y así es también como muchos exegetas y aun historiadores vierten el término. Ahora bien, es crucial percatarse de que esta traducción es errónea y engañosa. El primer problema surge de la observación de la naturaleza misma del suplicio: el robo no era considerado merecedor de pena capital, y en particular no de una ejecución tan elaborada como una crucifixión. De hecho, durante el período de control romano de Judea desde el 63 a.e.c. al menos hasta la Guerra Judía, los testimonios disponibles indican que el crudelissimum taeterrimumque supplicium ${ }^{115}$ se aplicó únicamente a rebeldes políticos y sus secuaces. ${ }^{116}$

El segundo factor a tener en cuenta estriba en que $\lambda \eta \eta \sigma \tau \alpha i ́$ es el término que Josefo utiliza con preferencia para referirse a los rebeldes que participaron en la revuelta contra Roma. ${ }^{117}$ El historiador judío usa la palabra con un significado derogatorio, pues estaba interesado en minimizar en lo posible tanto la dimensión religiosa como la legitimidad de la revuelta, y en denigrar a los rebeldes con el objeto de poder canalizar la responsabilidad de la violencia en una minoría de meros "bandidos". ${ }^{118}$ Esto muestra que el término puede ser usado no solo descriptivamente, sino también como una etiqueta insultante y oprobiosa, que no habría sido usada como autodesignación

114 Obsérvese que el hecho de que el Testimonium Flavianum (AJ XVIII, 63-64) mencione solo la crucifixión de Jesús no puede aducirse como prueba contra una crucifixión colectiva, pues la mención del cabecilla puede considerarse metonímica. Cuando Josefo menciona que Tiberio Alejandro hizo crucificar a los dos hijos de Judas, no puede descartarse que con ellos fueran ejecutados algunos de sus seguidores: solo ellos dos son mencionados, en calidad de cabecillas y por tanto de individuos más relevantes.

115 Cic., Ver. II 5, 165.

116 Cf. Kuhn 1982, 724. Cf. Dig. 48, 19, 28 § 15; Dig. 48, 19, 38 §§ 1-2. Es cierto que Josefo cuenta que el procurador Gesio Floro (64-66 e.c.) hizo crucificar a muchos individuos moderados, incluyendo a judíos de rango ecuestre ( $B J$ II, 306-308), pero en este caso varias circunstancias deben tenerse en cuenta. Primera, este es el resultado de episodios de los que solo conservamos la versión de Josefo, según el cual, después de que Floro se hubiera apoderado de una parte del tesoro del Templo (quizás para compensar los atrasos del pago del tributo a Roma), se produjeron protestas en Jerusalén y burlas al procurador; significativamente,

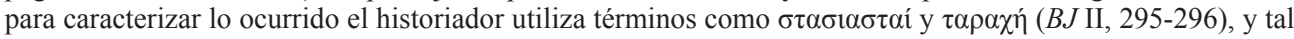
vez el hecho de que Floro decidiese acudir a Jerusalén con sus tropas de infantería y caballería se debiese a la gravedad de los acontecimientos. Segunda, la violencia de las tropas romanas se desata tras el intento fallido del procurador de identificar a los culpables de las acciones oprobiosas que habían tenido lugar, en virtud de la negativa de las autoridades judías a colaborar (BJ II, 301-305). Tercera, Josefo aclara explícitamente que la crueldad desplegada a continuación por Floro carecía de precedentes en el gobierno romano (BJ II, 308). Así pues, si bien por una parte es difícil obtener certeza sobre el grado de arbitrariedad de la conducta del procurador, por otra parece estar claro el carácter del todo excepcional de sus desafueros.

117 Cf. v. gr. $A J$ XVII, 271, 285; XVIII, 274; XX, 160, 163, 168, 172.

118 Marcus 1992. Si es lícito datar el Evangelio de Marcos ca. 70, es una época en la que el activismo revolucionario había penetrado incluso en la elite que gobernaba Judea; cf. GoODMAN 1987, 167-175. 
por los resistentes antirromanos. ${ }^{119} \mathrm{El}$ aspecto interesante de este uso polémico de $\lambda \eta ̣ \sigma \tau \alpha i$ es que también los autores de los evangelios estaban interesados en denigrar a los hombres crucificados con Jesús, con el objeto de crear una distinción nítida entre ellos y el héroe de sus relatos ${ }^{120}$-una estrategia, por cierto, que se reencuentra hasta extremos desconcertantes en ciertos autores modernos-. ${ }^{121}$

El tercer factor relevante en una interpretación correcta del término $\lambda \eta\rceil \tau \alpha i ́$ es contextual. Como hemos visto anteriormente, Marcos contiene una referencia a una

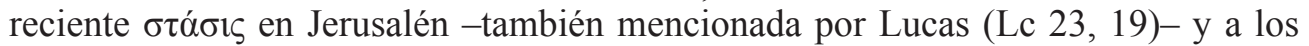
$\sigma \tau \alpha \sigma \iota \alpha \sigma \tau \alpha i ́$ que habían participado en ella. ${ }^{122}$ Este hecho, así como la presencia de otro material ya examinado $(\mathrm{Lc} 13,1)$, revela la existencia de una atmósfera sediciosa que corrobora la interpretación de $\lambda \eta ฺ \sigma \alpha \alpha i ́$ como insurgentes.

El conjunto de todos estos elementos convergentes indica que la hipótesis con

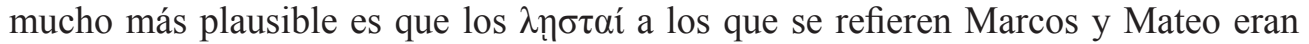
judíos nacionalistas que habían participado en algún tipo de acción antirromana. ${ }^{123}$ Así pues, mientras que la traducción habitual del término como "ladrones" es errónea, la de "bandidos" es desorientadora sin aclaraciones ulteriores, pues impide una comprensión fundada del episodio. ${ }^{124} \mathrm{De}$ hecho, en la perspectiva de los movimientos judíos de resistencia, esos hombres habrían sido héroes y luchadores por la libertad, mientras que solo en perspectiva imperial habrían sido simples criminales. Ahora

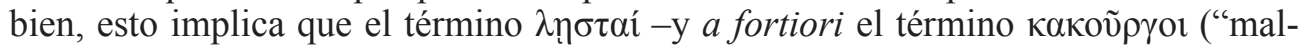
hechores") usado en Lc 23, 32-33- no constituye una caracterización imparcial y fiable de la identidad de esos sujetos, pues asume interesadamente la perspectiva del Imperio Romano sobre ellos.

Independientemente de lo que se opine sobre las causas de esta ejecución colectiva, ${ }^{125}$ y de si se acepta o no la hipótesis de que todos los ejecutados en el Gólgota estaban relacionados entre sí, ${ }^{126}$ lo cierto es que la noticia evangélica sobre

119 "Banditry was often defined by the winning side of a power struggle. For example, Iulius Caesar and Octavian had both been called bandits at one time, even though (as Augustus) Octavian became the

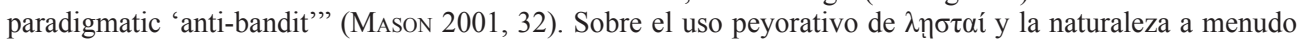
política de los calificados con este término, cf. RHOADs 1976, 159-162; SHAW 1984; GRÜNEWALD 2004, 91-109.

120 Las tendencias filorromanas de los evangelistas han sido señaladas convincentemente en la historia de la investigación. Cf. v. gr. WinTER 1974²; BRANDON 1967.

121 Así, Ernst Bammel sostuvo que, mientras la ejecución de los $\lambda \eta \emptyset \sigma \tau \alpha i ́$ "was entirely a Roman matter", Jesús fue crucificado por los judíos (BAMMEL 1984, 443).

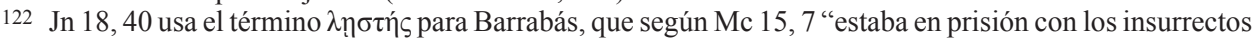
( $\mu \varepsilon \tau \grave{\alpha} \tau \tilde{\omega} \nu \sigma \tau \alpha \sigma 1 \alpha \sigma \tau \tilde{\omega} \nu) "$.

123 El término ליסטים, aparentemente la forma hebraizada del griego que se halla en las fuentes rabínicas, es traducido por algunos estudiosos como "guerrilla fighters"; cf. IsAAC 1990, 84-85. Ya Hengel había hablado,

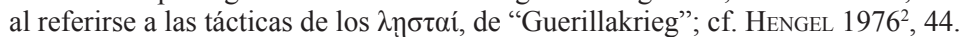

124 Esta interpretación comienza ya con los propios evangelistas, en la medida en que su intento de separar nítidamente a estos tipos del presuntamente inocente Jesús los llevó a dar de ellos una visión negativa, como individuos que insultan a Jesús o como criminales que incluso se autoinculpan (cf. Lc 23, 39-41).

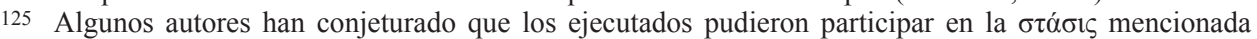
por Marcos y Lucas, algo tanto más plausible cuanto que en ella tuvo lugar derramamiento de sangre. Otros consideran la ejecución el resultado de alguno de los episodios que los evangelios atribuyen al grupo de Jesús en los que se hallan rastros del empleo de violencia, como los incidentes del Templo y Getsemaní.

126 Sobre este aspecto, cf. BERMEJo 2013. 
una crucifixión colectiva ordenada por Pilato constituye otro testimonio de represión por parte del poder romano que a su vez presupone -como el episodio de los galileos aludido en Lc 13- una acción de resistencia organizada por parte de un grupo de nacionalistas judíos.

\section{Evangelios canónicos (II): la historia central}

Material relevante para nuestro tema no se encuentra en los evangelios únicamente en la información circunstancial analizada, sino también en la historia central que narran, referida al predicador Jesús el galileo. ${ }^{127} \mathrm{El}$ hecho de que la tradición evangélica recuerde a su protagonista esencialmente como un maestro espiritual y taumaturgo no debería inducir al -muy frecuente- error hermenéutico de concluir que su trayectoria careció de dimensión política. No se trata solo de evitar incurrir en el anacronismo consistente en considerar lo religioso y lo político como dimensiones necesariamente separadas. ${ }^{128}$ Por una parte, existen en los evangelios rastros -mucho más numerosos y elocuentes de lo que suele reconocerse- de la significación política del mensaje y la actividad del predicador galileo. Por otra, los relatos de la pasión de Jesús contienen abundantes inconsistencias y noticias implausibles, lo que apunta a una considerable edición del material original, ${ }^{129}$ y precisamente en el sentido de una despolitización. ${ }^{130}$ Esto implica la necesidad de proceder a una reconstrucción crítica de la historia original subyacente a los relatos conservados. Si bien tal reconstrucción es con pasmosa frecuencia soslayada en virtud de intereses extraepistémicos, la probable dimensión política de la historia original que vertebra los evangelios ha sido señalada por la investigación independiente a más tardar desde el s. XVIII. ${ }^{131}$

La inclusión de Jesús en una crucifixión colectiva representa un conveniente punto de partida, pues sitúa ineludiblemente el destino del galileo en clave política. El dato de la crucifixión, no obstante, es solo un punto de partida, en la medida en que, dada la frecuente arbitrariedad e injusticia con la que los seres humanos que detentan poder condenan y torturan a sus congéneres, el mero hecho de ser víctima de una ejecución no prueba eo ipso la implicación del condenado en ideología y/o actividad antirromana, y por tanto su carácter insurgente. Existe, sin embargo, gran cantidad de material evangélico que permite confirmar esa presunción con suficiente seguridad.

\footnotetext{
127 A pesar de los reiterados intentos (desde el s. XVIII) de mostrar la falta de historicidad del personaje y su carácter mítico, parto aquí de que la historicidad del personaje - por supuesto, no de la imagen que los evangelios transmiten de él- es la hipótesis más simple y explicativa de los testimonios disponibles.

128 Josefo, que fue claro sobre el carácter antirromano de Judas el Galileo, consideró a este un maestro con

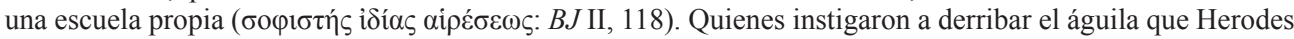
había erigido sobre la puerta del Templo -y que parece haber tenido un significado (también) político- eran,

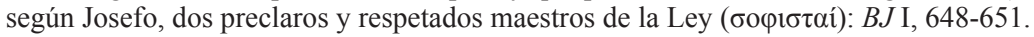

129 Excluyo aquí el uso de términos como "tergiversación" o "mistificación", que delatan una visión simplista de procesos que a menudo se producen, al menos en buena medida, de modo inconsciente.

130 Este proceso de despolitización ocurrido en la tradición evangélica ha sido reconocido incluso por exegetas provenientes del ámbito confesional; cf. DAVIES 1994² 344.

131 Además de Reimarus, cf. Eisler 1929-1930; Brandon 1967; Maccoby 1973; Montserrat 2007; PiÑero 2010; BeRMEJo 2013; ID. 2013a; ID. 2014; ID. 2014a; ID. 2015.
} 
Dado que este punto ha sido demostrado con frecuencia, en lo que sigue me limito a enumerar algunos aspectos fundamentales, abandonando de entrada todo prurito de exhaustividad: el enfático anuncio de una inminente instauración del Reino de Dios posee obvias implicaciones políticas, ya porque presupone el anhelo de una pronta desaparición del Imperio Romano; el carácter integral -no meramente etéreo o puramente "espiritual"- de ese Reino se transparenta en varios dichos atribuidos a Jesús que se refieren a la materialidad de las recompensas escatológicas, y se refleja también en las expectativas generadas por el personaje en sus discípulos; ${ }^{132}$ la pretensión regio-mesiánica del personaje, aunque puesta en sordina en los evangelios, es susceptible de ser reconstruida a partir de abundante material ${ }^{133}$ la lectura interna de Mc 12, 13-17 - a fortiori a la luz de Lc 23, 2- permite deducir que la posición de Jesús debió de ser contraria al pago del tributo a Roma; ${ }^{134}$ el carácter armado del grupo de Jesús, al menos en la etapa final del movimiento, se deduce de toda una serie de perícopas; $;{ }^{135}$ los evangelios -en especial en el incidente mal llamado de "la purificación del Templo"- contienen rastros de disturbios causados por Jesús en Jerusalén; ${ }^{136}$ Jn 11, 47-50 presupone una conexión entre el progreso del grupo de Jesús y una segura intervención violenta por parte de las tropas romanas. La convergencia de estos elementos -que son solo una exigua parte del material relevante-revela un patrón de recurrencia que permite vislumbrar la implicación de Jesús y su grupo en ideología y actividad antirromanas.

A esta luz, numerosos aspectos ulteriores de la historia evangélica se vuelven comprensibles en el contexto de la resistencia al Imperio. Estos no se limitan, en efecto, al tipo de ejecución que Jesús compartió con miles de resistentes, incluyendo a los hijos de Judas el Galileo Jacobo y Simón. El compromiso y la confianza a ultranza en la ayuda de Dios se concreta - al igual que en la posición de Judas el Galileo- en la disponibilidad a sufrir y dar la vida, incluso hasta el suplicio de la cruz, por el ideal de la restauración de Israel. ${ }^{137}$ Varios pasajes testimonian una actitud nacionalista o revelan prejuicios anti-paganos, hasta el punto de inducir a algunos autores a referirse a la actitud "chauvinista" de Jesús. ${ }^{138}$ La pretensión regio-mesiánica de Jesús tiene su paralelo en el hecho de que las revueltas surgidas en Galilea, Perea y Judea a la muerte de Herodes fueron movimientos en que los rebeldes parecen haber aclamado a uno de los suyos como rey, ${ }^{139}$ y en que varios líderes surgidos durante la Guerra Judía

\footnotetext{
132 Lc 24, 21; Hch 1, 6 .

133 Así lo ha hecho recientemente, con buenos argumentos, Allison 2010, 233-240, 247-254. La afirmación "Es un dato cierto que Jesús durante su vida pública no se proclamó a sí mismo mesías o rey" (PÉrez Fernández 2003, 109) es, para decirlo suavemente, un juicio temerario que depende de una lectura acrítica del material evangélico.

134 Cf. Brandon 1967, 345-348; Maccoby 1973, 132-3; Horsley 1993², 306-317; OAKman 2012, 127.

135 Sobre la historicidad de este dato, cf. Bermejo 2013, 146-147; Martin 2014.

136 Mc 11, 1-11; Mc 11, 15-19.

137 Sobre este aspecto, cf. FARMER 1956, 65-68; Hengel 1976², 261-277. Se ha conjeturado que el dicho sobre "llevar la propia cruz" (cf. Mc 8, 34-35 y par.; Mt 10, 38/Lc 14, 27) pudo ser originalmente una formulación proveniente de la resistencia antirromana; cf. HENGEL 1976², 266; Brandon 1967, 57, 145, 269; BRANDON 1968, 147.

138 Cf. v. gr. WINTER $1974^{2}, 193$.

139 BJ II, 56-65; AJ XVII, 271-284 (Judas, Simón, Atronges); AJ XVII, 285.
} 
parecen haber tenido pretensiones regias, como es el caso del Menajén descrito por Josefo como hijo de Judas -quien volvió a Jerusalén como un rey (oĩ $\delta$ j̀ $\beta \alpha \sigma \imath \lambda \varepsilon u ́ s$ ) acompañado por su séquito, y es más tarde presentado rezando en el Templo portando vestiduras reales. ${ }^{140}$ La hipótesis según la cual Jesús se opuso al pago del tributo hace de él un eslabón en la cadena que va de Judas el Galileo a los rebeldes de la primera Guerra Judía: para todos ellos, el tributo al César resultaba intolerable, pues significaba transferir los recursos de la Tierra Santa de Dios para el mantenimiento de un poder pagano. ${ }^{141}$ De hecho, Jesús comparte con Judas y los insurgentes de la Guerra Judía una comprensión radical de la teocracia, que admite solo a Dios como único señor y soberano. ${ }^{142}$ La animadversión entre Herodes Antipas y Jesús depende no solo del hecho de que el primero hizo ejecutar a quien parece haber sido su mentor, Juan el Bautista, ${ }^{143}$ sino ya del carácter filorromano del tetrarca. ${ }^{144}$ Lo mismo cabe observar sobre los conflictos y críticas de Jesús a la aristocracia sacerdotal de Jerusalén, cuyos miembros eran despreciados por los patriotas nacionalistas que ansiaban la libertad de Israel, que los percibían como colaboracionistas con el Imperio pagano. La dura crítica de Jesús a los ricos, ${ }^{145}$ en la medida en que la riqueza es asociada a la injusticia social y a la opresión, tiene igualmente un paralelo en la posición de los levantiscos que -en la estela de la tradición profética- eran hostiles a los estamentos más favorecidos de la población; de hecho, los movimientos rebeldes tuvieron generalmente un aspecto social, como es por ejemplo perceptible en la quema de los archivos públicos de Jerusalén durante los disturbios que marcaron el comienzo de la revuelta en el 66 e.c. ${ }^{146}$

Una vez señalados tales paralelismos, conviene llamar la atención sobre el hecho de que el carácter nacionalista del mensaje de Jesús se hace comprensible no solo a la luz de la existencia de una larga tradición judía de resistencia a gobernantes opresivos (extranjeros o propios), sino también específicamente dada su procedencia galilea. Cuando Jesús se hallaba en su infancia, las legiones romanas quemaron los pueblos en torno a Magdala y Séforis, y mataron o esclavizaron a miles de personas; ${ }^{147}$ la memoria de estas masacres debe de haber persistido largo tiempo en Galilea. Además, Jesús parece haber estado en su adolescencia cuando Judas hizo su llamamiento a resistir el censo y el dominio romano, y a no aceptar otro señor junto a Dios. ${ }^{148}$ Por

140 BJ II, 434.444. Simón bar Giora apareció ante los romanos vestido de púrpura: BJVII, 29.

141 Cf. Hengel $1976^{2}, 132-145$.

142 Léase el discurso puesto en boca de Eleazar ben Ari, el comandante de Masada, en BJ VII, 323.

143 Según el testimonio convergente de Josefo (AJ XVIII, 116-119) y los evangelios (Mc 6, 14-29).

144 Antipas debe de haber sido claramente percibido como un cliente de Roma, no solo porque fue educado allí y debía su posición a la beneficencia del emperador, sino también porque cambió el nombre de algunas poblaciones importantes en honor de la casa imperial, y construyó además Tiberíades en honor de Tiberio. Sobre las estrechas relaciones de los herodianos con Roma, cf. WILKER 2007; CURRAN 2014.

145 La tradición cristiana ha intentado mitigar estas críticas todo lo posible, como se expresa de forma paradigmática en el escrito de Clemente de Alejandría, Quis dives salvetur.

146 BJ II, 427. Las concomitancias de la historia narrada en los evangelios con aspectos de la Cuarta Filosofía son tan obvias que han sido reconocidas incluso por aquellos estudiosos que, sin embargo, se esfuerzan en minimizarlas o negarlas de todos los modos posibles. Cf. v. gr. HeNGEL 1976², 385-386.

147 AJ XVII, 289-291; BJ II, 68-71.

148 Cf. Brandon 1967, 29, 65, 343-344; Brandon 1968, 30-31. 
supuesto, estas circunstancias no prueban que la reacción de Jesús haya sido antirromana -aparte de que una resistencia no violenta habría sido también posible-; es más bien la cantidad de indicios en los evangelios que dejan traslucir un mensaje y una actividad rebeldes lo que hace de la procedencia galilea de Jesús un dato significativo.

A los análisis anteriores conviene añadir que todo intento de establecer una distinción nítida entre la historia de Jesús y la de la resistencia antirromana queda invalidado de antemano cuando se admite, por un lado, la seriedad de la inspiración religiosa de al menos una parte de los movimientos de oposición al Imperio, desde los Macabeos hasta los resistentes de la Guerra Judía, pasando por la "Cuarta Filosofia" de Judas el Galileo; ${ }^{149}$ y, por otro, la variabilidad de esos movimientos, susceptibles de expresar de modos diversos, de acuerdo a sensibilidades diferenciadas, el ideal común. ${ }^{150}$ De hecho, un error funesto de las aproximaciones al uso estriba en la incapacidad para comprender que, a diferencia de la posición colaboracionista, los movimientos de resistencia al Imperio estaban mancomunados por convicciones y disposiciones vitales fundamentales -empezando por la disponibilidad a entregar la propia vida-, y que por tanto las diversas opciones del nacionalismo judío no son antitéticas, sino complementarias. La historia central de los evangelios canónicos adquiere pleno sentido en este panorama.

Dado que, a pesar de que podemos estar prácticamente seguros de que las fuentes evangélicas han sido editadas, no podemos estarlo del alcance de esa edición, no es posible albergar certeza sobre el modo concreto en que Jesús estuvo implicado en actividad antirromana. Algunos estudiosos han reconstruido un escenario en el que se contempla un golpe de mano en Jerusalén, que luego habría sido cancelado en las fuentes. ${ }^{151}$ Otros han conjeturado que la presencia de Jesús acompañado de un grupo armado en el Monte de los Olivos podría explicarse a la luz de sus intensas convicciones escatológicas: en la probable espera de una inminente manifestación de Dios para instaurar su reino, el grupo habría querido secundar tal intervención celestial. ${ }^{152}$ De cualquiera de ambas hipótesis se deduce, no obstante, que Jesús y sus seguidores esperaron fervientemente el fin inminente del dominio imperial, y que intentaron tomar parte activa en él. Así pues, sea como fuere, lo que a la luz de lo señalado en esta sección sí resulta extremadamente probable es que el caso de Jesús puede y debe ser considerado no solo un episodio del heteróclito judaísmo del Segundo Templo, sino también un capítulo en la historia de la resistencia judía antirromana.

149 Esto fue demostrado por HeNGEL 1976²; FARMER 1956.

150 En muchas presentaciones habituales, el establecimiento de un contraste tajante entre la figura de Jesús y los rebeldes antirromanos es posible solo a costa de presuponer de modo simplista la naturaleza uniforme de esa resistencia.

151 Esta es la tesis de autores como Reimarus, Eisler, Brandon, Carmichael o Montserrat, entre otros.

152 Maccoby 1973; Bermejo 2013; Martin 2014. La actitud postulada por esta visión resulta similar a la de otros piadosos judíos contemporáneos, como la comunidad que produjo los textos de la guerra de Qumrán, cuya expectativa escatológica incluía una guerra final contra las Tinieblas en la que los "hijos de la luz" participarían en la batalla, en formación militar, junto con las huestes angélicas. 


\section{Releyendo a Tácito (Hist. V, 9, 2)}

El frecuente recurso a Tácito en el diseño de una imagen deliciosamente pacífica de Judea bajo los prefectos ha sido ya señalado. Si un historiador de su talla pudo escribir que hubo "tranquilidad bajo Tiberio", esto solo puede significar-se pretende- lo que significa prima facie. A la luz de los análisis efectuados, sin embargo, hay razones para desconfiar de la credibilidad de esta afirmación como dotada de validez general. Conviene, pues, examinar con más detenimiento el texto de Tácito, y considerar la posibilidad de que su sentido pueda ser diverso del que presenta a primera vista.

De entrada, es preciso señalar lo irónico que resulta que el texto de Tácito que suele citarse para postular la paz en Judea haga referencia a renglón seguido al recurso de los judíos a las armas. La frase completa, en efecto, reza así: "Bajo Tiberio hubo tranquilidad; cuando entonces C. César ordenó erigir una estatua suya en el Templo prefirieron recurrir a las armas, poniendo fin la muerte del César a esta revuelta (Sub Tiberio quies; dein iussi a C. Caesare effigiem eius in templo locare arma potius sumpsere, quem motum Caesaris mors diremit)". Solo la muerte de Calígula evita la iniciativa armada a la que el pueblo judío estaba dispuesto ante tal osada iniciativa.

Dado que, como hemos considerado, las fuentes examinadas testimonian la existencia de diversos episodios de resistencia, ¿qué significa entonces la declaración "bajo Tiberio (hubo) tranquilidad"? Una primera posibilidad es que la frase refleje la perspectiva poco informada de un historiador que, escribiendo en Roma, ignorase los acontecimientos ocurridos en una provincia lejana cuya gestión correspondía a un prefecto de rango ecuestre y no exigía por tanto la implicación directa del emperador. Así, podría pensarse que alguien que no estuviese especialmente interesado en los asuntos locales de Judea no tendría por qué haber estado enterado de los eventos que tuvieron lugar bajo Pilato. No obstante, dado no solo que Tácito disponía generalmente de mucha información, sino también que Josefo cuenta lo relativo a Pilato, y que había muchas personas en Roma -judíos y cristianos, pero también romanos- en época de Tácito que habrían estado interesadas en lo sucedido en Judea en las décadas anteriores no resulta plausible atribuir la frase a mera ignorancia.

Otra posibilidad, más plausible, estriba en considerar la frase como una declaración genérica que indica la ausencia de actividad militar a gran escala, y en particular el hecho de que el legado de Siria no hubo de intervenir con las legiones que tenía a su disposición -y de que, por tanto, el prefecto de Judea pudo solventar los problemas con sus propias tropas- ${ }^{153}$ Esta interpretación parece refrendada por el hecho de que Tácito no menciona disturbio alguno en el período que media entre la muerte de Herodes y el intento de Calígula de profanar el Templo mediante la erección de una estatua suya -momentos problemáticos a los que sí se refiere-; ahora bien, en la primera ocasión tuvo lugar la intervención de Quintilio Varo, mientras que en la segunda se produjo la del gobernador de Siria Publio Petronio.

Resulta obvio que entender la frase como una declaración genérica no implica la completa ausencia de disturbios en la provincia de Judea, ni la ausencia de una inter-

153 Cf. Crossan 1991, 101-102. 
vención allí de las autoridades romanas. El prefecto de Judea tenía a su disposición varias cohortes y tropas auxiliares, que ascendían a varios miles de hombres y cuyo grueso estaba estacionado en Cesarea Marítima, ${ }^{154}$ con las cuales habría sido posible controlar tentativas aisladas de rebelión o amotinamiento, como ocurrió de hecho con

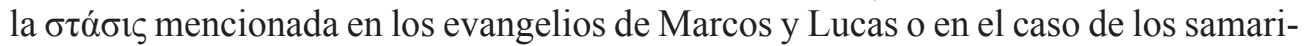
tanos. Por lo demás, en Galilea y Perea el tetrarca prorromano Herodes Antipas tenía también tropas propias a su disposición con las que controlar a los posibles elementos insurgentes en sus territorios. ${ }^{155}$

Recientemente, se ha argumentado que con la frase sub Tiberio quies Tácito parece estar usando a Tiberio como contraste para Calígula, cuyo nombre aparece a renglón seguido. ${ }^{156}$ Este tipo de contraposiciones es, de hecho, bien conocido en la historiografía antigua, y es en particular muy del gusto de Tácito. En su Legatio ad Caium, Filón contrapone a Calígula una serie de emperadores que habían mostrado respeto por el judaísmo y por sus instituciones, y uno de los mencionados es Tiberio. ${ }^{157}$ Josefo utilizó este procedimiento en Bellum, donde los encomios de ciertos procuradores cumplen la función de denigrar más eficazmente a otros cuya incompetencia el historiador sitúa como origen del descontento popular y como una de las causas de la guerra. ${ }^{158}$ Dada la tendencia a denigrar a Calígula en la historiografía romana, ${ }^{159}$ Tácito parece estar haciendo algo similar mediante una amplificatio: a diferencia de los tiempos del aborrecido Calígula, en el período del emperador previo Judea habría gozado de paz.

Una vez que se entiende la frase del historiador como, por una parte, una generalización simplificadora y, por otra, una exageración retórica no ajena a la polémica, puede dejar de considerarse como una descripción lo bastante precisa, y por tanto se entenderá mejor la conveniencia de excluirla del ámbito argumentativo como fundamento suficiente de una valoración fiable. Las anteriores consideraciones muestran que aducir la frase de Tácito en apoyo de una lectura de Josefo y de los evangelios que minimiza todo lo posible los rastros de resistencia antirromana-como se hace con llamativa frecuencia- entraña un considerable error hermenéutico.

154 Cf. Speidel 1982/3. No en vano Cesarea es llamada Iudaeae caput (Tac., Hist. II, 78).

155 Tenemos indicios de que lo hizo: Josefo narra que Antipas hizo detener, encerrar en la fortaleza de Maqueronte, y más tarde ejecutar por decapitación, a Juan el Bautista; el lenguaje utilizado por el historiador ( $A J$ XVIII, 116-119) delata que los temores del tetrarca fueron de signo político.

156 Schwartz 2013, 134-136.

157 Legat. ad Caium 294-329, especialmente 299-305.

158 Cf. v. gr. BJ II, 271 (encomio de Festo en comparación con Albino: II 272-276); BJ II, 277 (contraposición de Albino y Gesio Floro).

159 A pesar del indudable carácter despótico de Calígula, puede sospecharse con fundamento que la tradición (especialmente Suetonio y Dión Casio) se ha recreado en ensuciar ulteriormente su nombre mediante exageración retórica, generalización de incidentes aislados o tardíos y la aplicación de los consabidos tópicos sobre tiranos; cf. CHARLESWORTH 1933. 


\section{Conclusiones y reflexiones ulteriores}

La escasez de fuentes para una reconstrucción de la historia sociopolítica de Judea en el s. I -y en particular para su primera mitad, la época en la que Judea estuvo casi siempre bajo el dominio directo de prefectos romanos de rango ecuestre- es un problema bien conocido. Esto hace que, con el objeto de obtener una visión lo más aquilatada posible, sea necesario recurrir a todos los testimonios disponibles, y al mismo tiempo practicar una lectura crítica que tenga en cuenta los condicionamientos ideológicos y retóricos de sus autores. La omisión de alguna de esas fuentes o su lectura sesgada puede repercutir en la malinterpretación de las otras, y desembocar por ello con extrema facilidad en una comprensión distorsionada del período.

El análisis que hemos llevado a cabo ha intentado evitar incurrir en tal error. Esto nos ha llevado a releer a Josefo y a Tácito, pero también a tener en cuenta de un modo mucho más conspicuo de lo habitual los evangelios canónicos, obras del s. I que -además de abundante material legendario, anacrónico y/o teológicamente determinado- han preservado algunas noticias fiables relativas a la historia de un predicador galileo y a algunos episodios de insurgencia contemporáneos; así pues, tanto cierta información periférica como la propia historia que vertebra estas fuentes pueden y deben ser usadas para una reconstrucción no solo de la pluralidad de judaísmos en el período del Segundo Templo sino también de la situación sociopolítica de Eretz Israel en el primer tercio del s. I e.c., so pena de condenarse a mantener una visión parcial $\mathrm{o}$ a repetir clichés.

Si bien una reconstrucción precisa de la situación sociopolítica en el período considerado no es posible, las circunstancias que se deducen de una lectura crítica de las fuentes están lejos de corresponder a la opinión generalizada, vertida o presupuesta en numerosos trabajos académicos, según la cual la época de los prefectos fue un período de tranquilidad. Aunque, ciertamente, los testimonios disponibles no permiten refrendar la opinión ocasionalmente vertida de que ese período lo fue de incesante revolución -no hay noticia de guerras ni rebeliones generalizadas-, tampoco legitiman oscilar al otro extremo del péndulo y postular de modo genérico una situación pacífica.

Es posible reconocer la existencia y particularidades de distintas fases dentro de la época de dominación romana, incluso en el seno del período que va de la muerte de Herodes a la Guerra Judía, ${ }^{160}$ sin que ello implique convertirlas en una suerte de compartimentos estancos. Admitir que tanto la fase correspondiente al cambio de era y la previa a la Guerra Judía estuvieron caracterizadas por un grado de turbulencia a todas luces mayor que el que caracterizó a la fase intermedia entre ambas no autoriza a entender esta en términos de simple quies. La injustificada conversión de una situación solo relativamente menos turbulenta en una cuasi-idílica constituye un obvio non sequitur. La falta de rigor implicada en esta inferencia está condicionada por un uso insuficientemente crítico de las fuentes, que comporta la omisión de datos relevantes y/o la minimización de los rastros de violencia y actividad antirromana. El

160 Así lo propusieron plausiblemente GUEVARA 1985 y Brown 1994, I, 677-679. La propuesta está dirigida contra una visión indiferenciada, contenida v. gr. en SCHÜRER 1973, 357. 
hecho de que muchos estudiosos incurran así en incongruencias resulta en extremo decepcionante ${ }^{161}$ y lleva a preguntarse qué puede haberlas causado.

La respuesta más socorrida sería la de que todo se debe a un error de percepción o razonamiento. No obstante, aunque a veces la adopción de una visión sesgada en el ámbito académico puede ser achacada a defectos de este tipo, en otras las incongruencias resultan tan obvias y persistentes que su atribución a un mero error no resulta creíble. Cuando autores generalmente cuidadosos construyen teorías basándose en hipótesis que no pueden ser apoyadas en las fuentes cabe sospechar que las falacias cometidas podrían deberse a la intervención de factores extraepistémicos en algún nivel del análisis. Esta sospecha aumenta cuando se tiene en cuenta un aspecto elemental en el que ya se habrá reparado. El período de los prefectos es, precisamente, aquel en el que el referente central de los textos del Nuevo Testamento, Jesús el galileo, transita de la adolescencia a la madurez, desarrolla su actividad pública y acaba siendo crucificado. Ahora bien, este personaje no es solo una figura del judaísmo del s. I, sino el referente de la religión actualmente mayoritaria, en la cual se ha asumido la imagen mitificada que ofrecen de él los evangelios y la tradición cristiana. Esto significa que lo relativo a esta imagen concita intereses de todo tipo. Y ello hace, a su vez, que el tratamiento del período en que Jesús vivió, lejos de ser siempre desinteresado e imparcial, sea susceptible de ser usado fácilmente con espurios fines apologéticos o polémicos.

De hecho, la existencia de una agenda ideológica que guía a menudo el análisis de la época de los prefectos ha sido sugerida anteriormente por algunos investigadores. Así, Daniel Schwartz ha apuntado que varios trabajos que versan sobre el tema tienen como claro objetivo refutar la tesis según la cual la figura de Jesús debería ser incardinada en el marco de la resistencia antirromana: ${ }^{162}$ si en el primer tercio del siglo I e.c. ese fenómeno de resistencia no existió, todo intento de establecer alguna asociación

161 Me limito a un par de ejemplos, entre los muchos que podrían ofrecerse. En un artículo de título programático, Barnett cita aprobadoramente la frase de Tácito; y aunque en su examen del período de Pilato afirma que hubo "gran tensión" (BARNETT 1975, 567-568) y menciona varios disturbios en los que se produjo derramamiento de sangre, ello no le lleva a variar su tesis. Otro caso conspicuo es el de Giblet. Aunque este autor admite a regañadientes la existencia de algunos episodios violentos y su relevancia ("Le fait indiquerait un certain climat d'effervescence favorable certes à la naissance d'entreprises organisées de résistance": GIBLET 1974, 424) prosigue afirmando que "il ne suffit pas à fonder l'existence d'un mouvement structuré de résistance nationaliste" (424-425), lo que le lleva a concluir: "Par contre à l'époque de Jésus, on n'aperçoit guère les signes d'une entreprise révolutionnaire ni surtout les indices d'opérations menées par des groupements révolutionnaires armés" (425). Ahora bien, no es solo que, dada la escasez de testimonios, no haya modo de saber si hubo o no un movimiento estructurado de resistencia, sino que de lo que se trata es de si los testimonios disponibles permiten averiguar si hubo en este período episodios de resistencia nacionalista, independientemente de si estos corresponden o no a la existencia de un movimiento unificado. En este sentido, es fácil mostrar también las deficiencias de la obra doctrinaria de Guevara: en su análisis de los pasajes relativos a ideología o actividad rebelde, aparte de su fallido tratamiento de Qumrán (GuEVARA 1985,176 reitera la idea del "pacifismo" esenio y afirma que 1QM no trata de una guerra real), del Nuevo Testamento este autor cita únicamente Hch 5, 21-33 (GuEvarA 1985, 213-220), silenciando así la práctica totalidad del material relevante. Sin comentarios.

162 SCHWARTZ 1992, 141 y n. 34; ID. 2013, 136, n. 68 ("Barnett's objective is clear: his article was devoted, explicitly, to refuting the thesis [...] that Jesus should be understood as an anti-Roman rebel, something Barnett attempted to do by arguing that such a phenomenon hardly existed in Jesus' days"). 
de Jesús con él carecería, por definición y a priori, de todo fundamento, y podría ser alegremente desechado. Algo similar ha sido señalado por Roland Deines en otro importante trabajo reciente. ${ }^{163}$

En realidad, los autores mencionados críticamente por estos estudiosos no son sino unos pocos ejemplos de una extendida situación historiográfica, en la cual se asiste a la descripción de una situación histórica mediante la -sin duda inconscientetergiversación de los testimonios disponibles con el objeto de defender una opinión preconcebida dictada por una visión a menudo confesional. Una determinada reconstrucción del período en que vivió Jesús como una época tranquila sirve, en efecto, de tácita legitimación a la negativa apriorística a considerar la implicación del protagonista de los relatos evangélicos en algún tipo de ideología y/o actividad insurgente antirromana, y por tanto como coartada para desechar de antemano la posibilidad misma de considerar al galileo un mártir de la resistencia judía, asociado a la causa nacionalista de la liberación de Eretz Israel. ${ }^{164}$ Debería resultar obvio el perjuicio que estos procedimientos, debidos en última instancia a una crasa determinación teológica, causan a una comprensión lúcida del período.

Esto significa que, de modo más o menos sutil, algunas ficciones de la "historia sagrada" -o bien ideas destinadas a apuntalarlas- siguen infiltrándose y siendo propaladas hasta hoy en la historia secular. Las conclusiones obtenidas en este estudio permiten, por una parte, mostrar el carácter insostenible y acrítico de aproximaciones ideológicamente condicionadas; por otra, comprender que, si bien el desvelamiento de los factores distorsionantes en la actividad académica suele constituir una labor ingrata y descorazonadora, representa también una tarea del todo imprescindible a la hora de efectuar una labor histórica digna de ese nombre.

\section{Bibliografía}

Allison, D. C. (2010): Constructing Jesus. Memory, Imagination, and History, Grand Rapids. AtKinson, $\mathrm{K}$.

(1996): "Herod the Great, Sosius and the Siege of Jerusalem (37 B.C.E.) in Psalm of Solomon 17", Novum Testamentum 38, 313-22.

(1998): "Toward a Redating of the Psalms of Solomon: Implications for Understanding the Sitz im Leben of an Unknown Jewish Sect", Journal for the Study of the Pseudepigrapha $17,95-112$.

(1999): "On the Herodian Origin of Militant Davidic Messianism at Qumran: New Light from Psalm of Solomon 17", Journal of Biblical Literature 118, 435-460.

(2004): I Cried to the Lord: A Study of the Psalms of Solomon's Historical Background and Social Setting, Leiden-Boston.

163 Refiriéndose a Brown 1994, Deines (2011, 411, n. 18) afirma que su análisis "von dem erkennbaren Bestreben getragen ist [...], die Prokuratur des Pilatus als relativ friedlich darzustellen, um damit alle Versuche, Jesus als Revolutionär [...] darzustellen, von vornherein als unhaltbar zurückweisen zu können”.

164 Así lo sugirió BRANDON (1967, 354-355): "There seems to be nothing in the principles [...] enunciated by Judas of Galilee, that we have definite evidence for knowing that Jesus would have repudiated". 
Ayaso, J. R. (1990): Iudaea Capta. La Palestina romana entre las dos guerras judías (70-132 d. C.), Estella.

Bammel, E. (1984): “The Trial before Pilate", [en] E. Bammel - C. F. D. Moule (eds.), Jesus and the Politics of His Day, Cambridge, 415-451.

Barnett, P. W. (1975): “Under Tiberius all was Quiet”, New Testament Studies 21, 564-571.

Batsch, C. (2004): “Le 'pacifisme des esséniens', un mythe historiographique”, Revue de Qumran 83, 457-468.

Bauman, R. A. (1967): The Crimen Maiestatis in the Roman Republic and Augustan Principate, Johannesburg.

BERMEJO, F.

(2012): "La figura histórica de Jesús y los patrones de recurrencia. Por qué los límites de los criterios de autenticidad no abocan al escepticismo", Estudios Bíblicos 70, 371-401. (2013): “(Why) Was Jesus Crucified Alone? Solving a False Conundrum", Journal for the Study of the New Testament 36, 127-154 (http://dx.doi.org/10.1177/0142064X13506166). (2013a): "Has the Hypothesis of a Seditionist Jesus Been Dealt a Fatal Blow? A Systematic Answer to the Doubters", Bandue 7, 19-57.

(2014): "Was the Hypothetical Vorlage of the Testimonium Flavianum a 'Neutral' Text? Challenging the Common Wisdom on Antiquitates Judaicae XVIII 63-64", Journal for the Study of Judaism 45, 326-365 (http://dx.doi.org/10.1163/15700631-12340055).

(2014a): "Jesus and the Anti-Roman Resistance. A Reassessment of the Arguments", Journal for the Study of the Historical Jesus 12, 1-105 (http://dx.doi.org/10.1163/17455197 01202001).

(2015): "Jesus as a Seditionist: the Intertwining of Politics and Religion in his Teaching and Deeds", [en] Z. Garber (ed.), Teaching the Historical Jesus. Issues and Exegesis, New York-London, 232-243.

(2015a): "El factor religioso en la resistencia judía al Imperio Romano en el s. I e.c. Cuestiones disputadas en torno a la 'Cuarta Filosofía", Bandue 9, en prensa.

BernheIm, E. (1908): Lehrbuch der historischen Methode und der Geschichtsphilosophie, Leipzig.

Berthelot, K. (2011): "Philo's Perception of the Roman Empire”, Journal for the Study of Judaism 42, 166-187 (http://dx.doi.org/10.1163/157006311X544373).

Blinzler, J. (1957): “Die Niedermetzelung von Galiläern durch Pilatus”, Novum Testamentum 2, 24-49.

Bond, H. K. (1998): Pontius Pilate in History and Interpretation, Cambridge.

BRANDON, S. G. F.

(1967): Jesus and the Zealots. A Study of the Political Factor in Primitive Christianity, Manchester.

(1968): The Trial of Jesus of Nazareth, London.

Brooke, G. (1991): “The Kittim in the Qumram Pesharim”, [en] L. Alexander (ed.), Images of Empire, Sheffield, 135-159.

Brownlee, W. H. (1983): "From Holy War to Holy Martyrdom", [en] H. B. Huffmon et alii (eds.), The Quest for the Kingdom of God: Studies in Honor of George E. Mendenhall, Winona Lake, 281-292.

Buitenwerf, R. (2003): Book III of the Sibylline Oracles and its Social Setting. With an Introduction, Translation, and Commentary, Leiden-Boston. 
Bultmann, R. (1970): Geschichte der synoptischen Tradition, Göttingen.

Burridge, R. A. (1992): What Are the Gospels. A Comparison with Graeco-Roman Biography, Cambridge.

Conen, S. J. D. $\left(2006^{2}\right)$ : From the Maccabees to the Mishnah, Louisville.

Charlesworth, M. P. (1933): “The Tradition about Caligula", The Cambridge Historical Journal 4, 105-119.

Chilton, C. W. (1955): “The Roman Law of Treason under the Early Principate", Journal of Roman Studies 45, 73-81 (http://dx.doi.org/10.2307/298746).

Collins, J. J. (1995): The Scepter and the Star. The Messiahs of the Dead Sea Scrolls and Other Related Literature, New York.

Cotтon, H. M. (1999): "Some Aspects of the Roman Administration of Judaea/Syria-Palaestina”, [en] W. Eck (ed.), Lokale Autonomie und römische Ordnungsmacht in der kaiserzeitlichen Provinzen vom 1.-3. Jahrhundert, München, 75-91.

Crossan, J. D. (1991): The Historical Jesus. The Life of a Mediterranean Jewish Peasant, New York.

Cullmann, O. (1961): Der Staat im Neuen Testament, Tübingen.

Curran, J. (2014): “Philorhomaioi: The Herods between Rome and Jerusalem”, Journal for the Study of Judaism 45, 493-522 (http://dx.doi.org/10.1163/15700631-12340097).

Dabrowa, E. (1998): The Governors of Roman Syria from Augustus to Septimius Severus, Bonn.

Davies, W. D. (1994²): The Gospel and the Land. Early Christianity and Jewish Territorial Doctrine, Sheffield.

DeInes, R. (2011): “Gab es eine jüdische Freiheitsbewegung? Martin Hengels 'Zeloten' nach 50 Jahren”, [en] M. Hengel, Die Zeloten, 3. ed., Tübingen, 403-448.

De Vaux, R. (1973): Archaeology and the Dead Sea Scrolls, Oxford.

ECK, W.

(2007): Rom und Judaea: Fünf Vorträge zur römischen Herrschaft in Palaestina, Tübingen.

(2011): "Die römischen Repräsentanten in Judaea: Provokateure oder Vertreter der römischen Macht?”, [en] M. Popović (ed.), The Jewish Revolt Against Rome. Interdisciplinary Perspectives, Leiden, 45-68.

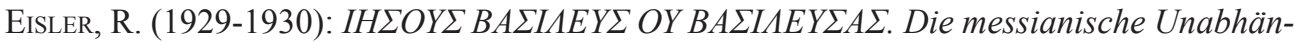
gigkeitsbewegung vom Auftreten Johannes des Täufers bis zum Untergang Jakobs des Gerechten, Heidelberg, 2 vols.

ESHEL, H.

(2001): "The Kittim in the War Scroll and in the Pesharim", [en] D. Goodblatt - A. Pinnick - D. R. Schwartz (eds.), Historical Perspectives from the Hasmoneans to Bar Kokhba in Light of the Dead Sea Scrolls. Proceedings of the Fourth International Symposium of the Orion Center for the Study of the Dead Sea Scrolls and Associated Literature, 27-31 January, 1999, Leiden-Boston, 29-44.

(2008): The Dead Sea Scrolls and the Hasmonean State, Grand Rapids.

FARMer, W. R. (1956): Maccabees, Zealots and Josephus: An Inquiry into Jewish Nationalism in the Greco-roman period, New York. 
FREYNE, S.

(1998): Galilee, from Alexander the Great to Hadrian 323BCE to 135CE. A Study of Second Temple Judaism, Edinburgh (ed. orig. 1980).

(2009): “The Herodian Period", [en] M. Bockmuehl - J. Carleton Paget (eds.), Redemption and Resistance. The Messianic Hopes of Jews and Christians in Antiquity, London, 29-43.

FrickensChMidT, D. (1997): Evangelium als Biographie. Die vier Evangelien im Rahmen antiker Erzählkunst, Tübingen.

GABBA, E. $\left(2001^{2}\right)$ : “The Social, Economic and Political History of Palestine 63BCE -CE 70", [en] W. Horbury - W. D. Davies - J. Sturdy (eds.), The Cambridge History of Judaism, vol. 3: The Early Roman Period, Cambridge, 94-168.

Giblet, J. (1974): “Un mouvement de résistance armée au temps de Jésus?”, Revue Théologique de Louvain 5, 409-429.

Goodblatt, D. (2006): Elements of Ancient Jewish Nationalism, Cambridge.

Goodenough, E. R. (1967): The Politics of Philo Judaeus. Practice and Theory, Hildesheim.

Goodman, M. (1987): The Ruling Class of Judaea. The Origins of the Jewish Revolt Against Rome A. D. 66-70, Cambridge.

GrünEwald, T. (2004): Bandits in the Roman Empire. Myth and Reality, London-New York (orig. alemán 1999).

Guevara, H. (1985): Ambiente político del pueblo judio en tiempos de Jesús, Madrid.

Hadas-Lebel, M. (1987): “L'évolution de l'image de Rome auprès des Juifs en deux siècles de relations judéo-romaines -164 à +70”, ANRW II 20 2, Berlin-New York, 715-856.

Heard, W. J. - Evans, C. A. (2000): "Revolutionary Movements, Jewish", [en] C. A. Evans S. E. Porter (eds.), Dictionary of New Testament Background, Nottingham, 936-947.

Hengel, M.

$\left(1976^{2}\right)$ : Die Zeloten: Untersuchungen zur jüdischen Freiheitsbewegung in der Zeit von Herodes I. bis 70 n. Chr., Leiden, (ed. orig. 1961).

(1971): Gewalt und Gewaltlosigkeit, Stuttgart.

Hezser, C. (2013): "Seduced by the Enemy or Wise Strategy? The Presentation of Non-Violence and Accommodation with Foreign Powers in Ancient Jewish Literary Sources", [en] R. Albertz - J. Wöhrle (eds.), Between Cooperation and Hostility. Multiple Identities in Ancient Judaism and the Interaction with Foreign Powers, Göttingen, 221-250.

Horsley, R. A.

$\left(1993^{2}\right)$ : Jesus and the Spiral of Violence, Minneapolis.

(2003): Jesus and Empire. The Kingdom of God and the New World Disorder, Minneapolis.

Horsley, R. A. - Hanson, J. S. (1999²): Bandits, Prophets \& Messiahs. Popular Movements in the Time of Jesus, Harrisburg.

IsAac, B. (1990): The Limits of Empire. The Roman Army in the East, Oxford.

Jossa, G. (1980): Gesù e i movimenti di liberazione della Palestina, Brescia.

KuHN, H.-W. (1982): "Die Kreuzesstrafe während der frühen Kaiserzeit. Ihre Wirklichkeit und Wertung in der Umwelt des Christentums", ANRW 25.1, Berlin-New York, 648-793.

Lagrange, M.-J. $\left(1941^{6}\right)$ : Évangile selon Saint Luc, Paris. 
De Lange, N. R. M. (1978): “Jewish Attitudes to the Roman Empire”, [en] P. D. A. Garnsey -

C. R. Whittaker (eds.), Imperialism in the Ancient World, Cambridge, 255-281.

LÉGAsse, S. (1994): Le procès de Jésus. L’histoire, Paris.

Loftus, F. (1977): "The Anti-Roman Revolts of the Jews and the Galileans", The Jewish Quarterly Review 68, 78-98.

Lönnquist, K. A. (2000): "Pontius Pilate-An Aqueduct Builder? Recent Findings and New Suggestions", Klio 82, 458-474.

Maccoby, H. (1973): Revolution in Judaea, London.

Marcus, J.

(1992): "The Jewish War and the Sitz im Leben of Mark", Journal of Biblical Literature 111, 441-462 (http://dx.doi.org/10.2307/3267261).

(1996): "Modern and Ancient Jewish Apocalypticism", The Journal of Religion 76, 1-27 (http://dx.doi.org/10.1086/489733).

(2009): Mark 8-16. A New Translation with Introduction and Commentary, New HavenLondon.

Martin, D. (2014): “Jesus in Jerusalem: Armed and Not Dangerous", Journal for the Study of the New Testament 37, 3-24 (http://dx.doi.org/10.1177/0142064X14544863).

MASON, S.

(1996): "Philosophiai: Graeco-Roman, Judean, and Christian", [en] J. S. Kloppenborg - S. G. Wilson (eds.), Voluntary Associations in the Ancient Mediterranean World, London, 31-58. (2001): Life of Josephus, Leiden.

(2005): "Of Audience and Meaning: Reading Josephus' Bellum Judaicum in the Context of a Flavian Audience", [en] J. Sievers - G. Lembi (eds.), Josephus and Jewish History in Flavian Rome and Beyond, Leiden, 71-100.

McLaren, J. S.

(1991): Power and Politics in Palestine. The Jews and the Governing of their Land 100 $B C-A D$ 70, Sheffield.

(2003): "The Coinage of the First Year as a Point of Reference for the Jewish Revolt", Scripta Classica Israelica 23, 135-152.

(2004): "Constructing Judean History in the Diaspora: Josephus's Accounts of Judas", [en] J. Barclay (ed.), Negotiating Diaspora: Jewish Strategies in the Roman Empire, LondonNew York, 90-108.

Mendels, D. (1992): The Rise and Fall of Jewish Nationalism, New York.

MildenberG, L. (1990): "Rebel Coinage in the Roman Empire", [en] A. Kasher et alii (eds.), Greece and Rome in Eretz Israel. Collected Essays, Jerusalem, 62-74.

Millar, F. (1987): "Empire, Community and Culture in the Roman Near East: Greeks, Syrians, Jews and Arabs", Journal of Jewish Studies 38, 143-164.

Montserrat, J. (2007): El galileo armado. Historia laica de Jesús, Madrid.

Nickelsburg, G. W. E. $\left(2005^{2}\right)$ : Jewish Literature between the Bible and the Mishnah. A Historical and Literary Introduction, Minneapolis (ed. orig. 1981).

Nikiprowetzky, V. (1989): “Josephus and the Revolutionary Parties”, [en] L. H. Feldman - G. Hata (eds.), Josephus, the Bible, and History, Leiden, 216-236.

Norden, E. (1913): “Josephus und Tacitus über Jesus Christus und seine messianische Prophetie," Neue Jahrbücher für das klassische Altertum 31, 637-666. 
Oakman, D. E. (2012): The Political Aims of Jesus, Minneapolis.

Pérez FernándeZ, M.

(1981): Tradiciones mesiánicas en el Targum palestinense. Estudios exegéticos, Valencia. (2003): “Jesús de Galilea”, [en] M. Sotomayor - J. Fernández Ubiña (eds.), Historia del cristianismo, I: El mundo antiguo, Madrid, 69-121.

PIÑERO, A. (2010): “Jesús y la política de su tiempo”, [en] E. Ruiz Barrachina, El discípulo, Barcelona, 217-311.

Pomykala, K. E. (1995): The Davidic Dynasty Tradition in Early Judaism. Its History and Significance for Messianism, Atlanta.

Portier-Young, A. E. (2011): Apocalypse against Empire. Theologies of Resistance in Early Judaism, Grand Rapids.

Price, J. J. (1992): Jerusalem under Siege: the Collapse of the Jewish State, 66-70 C.E, Leiden.

Puech, É. (1992): “Fragment d'une apocalypse en araméen (4Q246 = pseudo-Dan') et le 'royaume de Dieu", Revue Biblique 99, 98-131.

RAppaport, U. (1992): “How Anti-Roman was the Galilee?”, [en] L. I. Levine (ed.), The Galilee in Late Antiquity, London, 95-102.

Rhoads, D. M. (1976): Israel in Revolution 6-74 C.E. A Political History Based on the Writings of Josephus, Philadelphia.

SAnders, E. P. (1992): Judaism: Practice and Belief 63 BCE - 66 CE, Philadelphia.

Sharon, N. (2012): "Setting the Stage: The Effects of the Roman Conquest and the Loss of Sovereignty", [en] D. R. Schwartz, Z. Weiss - R. A. Clements (eds.), Was 70 CE a Watershed in Jewish History? On Jews and Judaism before and after the Destruction of the Second Temple, Leiden, 415-445.

Schultz, B.

(2009): Conquering the World. The War Scroll (1QM) Reconsidered, Leiden.

(2012): "Re-imagining the Eschatological War - 4Q285/11Q14", [en] A. M. Maier - J. Magness - L. H. Schiffman, "Go Out and Study the Land” (Judges 18:2), Archaeological, Historical and Textual Studies in Honor of Hanan Eshel, Leiden, 197-212.

Schürer, E. (1973): The History of the Jewish People in the Age of Jesus Christ (175 B.C. A.D. 135), vol. I, A New English Version Revised and Edited by G. Vermes \& F. Millar, Edinburgh.

SCHWARTZ, D. R.

(1992): Studies in the Jewish Background of Christianity (=WUNT 60), Tübingen.

(2013): Reading the First Century. On Reading Josephus and Studying Jewish History of the First Century (=WUNT 300), Tübingen.

Shaw, B. D. (1984): "Bandits in the Roman Empire", Past and Present 105, 3-52 (http:// dx.doi.org/10.1093/past/105.1.3).

Sherwin-White, A. N. (1984): Roman Foreign Policy in the East: 168 B.C. to A.D. 1, London.

Sicre, J. L. (2003): "El legado judío”, [en] M. Sotomayor - J. Fernández Ubiña (eds.), Historia del cristianismo, I: El mundo antiguo, Madrid, 17-68.

Smallwood, E. M. (1981): The Jews under Roman Rule, from Pompey to Diocletian. A Study in Political Relations, Leiden. 
Sмiтh, M. (20012): “The Troublemakers", [en] W. Horbury - W. D. Davies - J. Sturdy (eds.), The Cambridge History of Judaism, vol. 3: The Early Roman Period, Cambridge, 501-568.

Speidel, M. P. (1982/3): “The Roman Army in Judaea under the Procurators”, Ancient Society $13 / 14,233-240$.

Spilsbury, P. (2003): "Flavius Josephus on the Rise and Fall of the Roman Empire", Journal of Theological Studies 54, 1-24 (http://dx.doi.org/10.1093/jts/54.1.1).

Stemberger, G. (1983): Die römische Herrschaft im Urteil der Juden, Darmstadt.

Theissen, G. - Merz, A. (1996): Der historische Jesus. Ein Lehrbuch, Göttingen.

Theissen, G. - Winter, D. (1997): Die Kriterienfrage in der Jesusforschung. Vom Differenzkriterium zum Plausibilitätskriterium, Göttingen.

Tromp, J.

(1993): "The Sinners and the Lawless in Psalm of Solomon 17", Novum Testamentum 35, 344-361 (http://dx.doi.org/10.1163/156853693X00211).

(1993a): The Assumption of Moses. A Critical Edition with Commentary, Leiden.

Van Den Horst, P. W. (1978): The Sentences of Pseudo-Phocylides with Introduction and Commentary, Leiden.

Vermes, G. (2001): Jesus the Jew. A Historian's Reading of the Gospels, London (ed. orig. 1973).

WebB, R. L. (2009): “The Roman Examination and Crucifixion of Jesus: Their Historicity and Implications", [en] D. L. Bock - R. L. Webb (eds.), Key Events in the Life of the Historical Jesus. A Collaborative Exploration of Context and Coherence, Tübingen, 669-773.

WILKER, J.

(2007): Für Rom und Jerusalem. Die herodianische Dynastie im 1. Jahrhundert n.Chr., Frankfurt am Main.

(2012): "God is With Italy Now'. Pro-Roman Jews and the Jewish Revolt", [en] B. Eckhardt (ed.), Jewish Identity and Politics between the Maccabees and Bar Kokhba. Groups, Normativity and Rituals, Leiden, 157-187.

Winter, P. (1974²): On the Trial of Jesus, Berlin (ed. orig. 1961). 